\title{
Turbulent Flame Propagation and Combustion in Spark Ignition Engines
}

\author{
G. P. BERETTA, M. RASHIDI, and J. C. KECK \\ Massachusetts Institute of Technology, Cambridge, MA 02139
}

\begin{abstract}
Pressure measurements synchronized with high-speed motion picture records of flame propagation have been made in a transparent piston engine. The data show that the initial expansion speed of the flame front is close to that of a laminar flame. As the flame expands, its speed rapidly accelerates to a quasi-steady value comparable with that of the turbulent velocity fluctuations in the unbumed gas. During the quasi-steady propagation phase, a significant fraction of the gas behind the visible front is unburned. Final burnout of the charge may be approximated by an exponential decay in time.

The data have been analyzed in a model independent way to obtain a set of empirical equations for calculating mass burning rates in spark ignition engines. The burning equations contain three parameters: the laminar burning speed $s_{l}$, a characteristic speed $u_{\mathrm{T}}$, and a characteristic length $l_{\mathrm{T}}$. The laminar burning speed is known from laboratory measurements. Tentative correlations relating $u_{\mathrm{T}}$ and $l_{\mathrm{T}}$ to engine geometry and operating variables have been derived from the engine data.
\end{abstract}

\section{INTRODUCTION}

Within the last decade, the historically established empirical method of developing an internal combustion engine has been intensively and progressively complemented by the science of modeling [1]. The reasons for this change are found in two main problems of our present society: the environmental problem, with the new constraints of strict emission standards, and the fuel shortage problem, with the consequent rising costs of the primary energy sources and the demand for more efficient use.

The empirical method of development cannot handle, in an economical way, the complex problem of optimizing efficiency at acceptable power levels subject to the new, rigid environmental and energy constraints. The principal goal of engine modeling is to provide a better analytical method for treating this problem. But there is also a less pragmatic reason for developing models that has received more and more attention: the desire to understand the governing physical mechanisms of the processes occurring in a real operating engine.

The latter task is obviously of great difficulty, since it involves going beyond the state of the art in all thermal sciences: nonequilibrium thermodynamics, chemical kinetics, unsteady fluid dynamics and turbulence-all coupled in one problem.

A number of different approaches have been tried to solve the modeling problem, and their success depends on how the calculated results compare with experiments. It is well known that turbulence plays a fundamental role in the operation of a real engine. Mathematical theories have been proposed to deal with this problem [2-8], but no established physical description of a turbulent flow is yet available. The physics of turbulent flame propagation is even less well understood [916]. For these reasons, an attempt has been made in the present work to define quantities and obtain experimental estimates independently of physical models, so that the resulting experimental evidence may be used to test the assumptions of any physical model. The aim has been to extract experimental information on that small but important 
portion of the whole operating cycle of the spark ignition engine where the combustion process takes place. This has been done by developing and applying a simple model independent method to analyze the data generated by coupling careful pressure measurements with high-speed photography of flame propagation [17].

After a brief description of the experiment, the method is presented and the results discussed. In accordance with the declared aim of the present work, physical interpretation of the results is left for future work. An attempt to provide some physical interpretation of the results, in the context of current combustion research, has been made by the last author in a recent review paper [18] based in part on the present work.

\section{EXPERIMENTAL APPARATUS AND MEASUREMENTS}

The experiments were carried out on a single-cyl. inder transparent piston spark ignition engine [19] . Figure 1 shows a schematic diagram of the pistoncylinder system which allows optical access to the combustion chamber through the quartz piston window. The cylinder head is that used by Ford on the 400 CID V-8 engine. Because optical access is obtained through the piston, the original chamber and valve configuration could be preserved. Table 1 gives the details of the engine geometry and valve timing.

The purpose of the experiments was to obtain pressure measurements synchronized with photographic records of the flame profiles through each single engine combustion cycle. High-speed motion pictures were made with a Hycam Model K-2001-R rotating prism camera capable of taking up to 5000 frames per second. In order to increase flame luminosity, the mixture of isooctane and air was seeded with uniformly suspended salts, appropriately chosen not to affect flame propagation. The edge of the film was marked every 20 crank angle degrees by a neon light pulse synchronized to the flywheel. Such markers provide a means of associating a crank angle with each frame of the photographic sequence. The engine pressure was measured using a silicone-coated Kistler model 609A piezoelectric transducer and a model 504E charge amplifier the output of which was $A / D$ converted

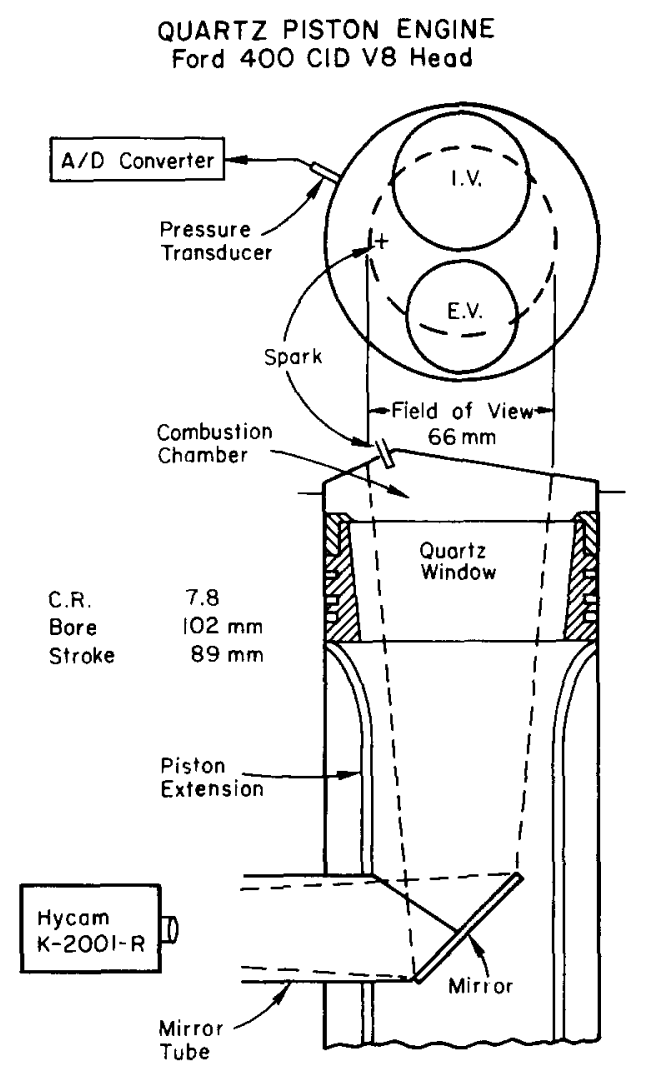

Fig. 1. Schematic of the M.I.T. quartz piston spark ignition engine used by Rashidi.

by an on-line DEC-PDP11 digital computer storing one pressure value every crank angle degree.

The experimental procedure was the following. First, the engine was motored for a sufficiently long time to reach a completely steady state. Then, an electronic switching system was activated for the following sequence of operations: start the high-speed camera; wait for its speed to reach a threshold value; light the spark for 10-13 cycles, and simultaneously activate the pressure data acquisition system.

As a result of this procedure, the complete data set for each cycle of a run consists of synchronized records of the cylinder pressure and the flame profile as a function of crank angle. Table 2 summarizes the operating conditions of the seven runs for which complete data sets were obtained.

A typical sequence of pressure traces as a function of crank angle for the first 10 firing cycles of run 2 is shown in Fig. 2. The "motored cycle" was 
TABLE 1

Engine Geometry

\begin{tabular}{|c|c|c|c|}
\hline Compression ratio & $C R$ & 7.86 & \\
\hline Bore & $b$ & $=101.6$ & $\mathrm{~mm}$ \\
\hline Stroke & $S$ & 88.9 & $\mathrm{~mm}$ \\
\hline Connecting rod length & $L_{\boldsymbol{r}}$ & $=147.0$ & $\mathrm{~mm}$ \\
\hline Clearance height & $h_{\text {TDC }}$ & 13.0 & $\mathrm{~mm}$ \\
\hline Equivalent wedge angle & $\eta$ & 0.17 & rad \\
\hline Inlet valve diameter & $D_{\text {IV }}$ & 48.3 & $\mathrm{~mm}$ \\
\hline Exhaust valve diameter & $D_{\mathrm{EV}}$ & 38.5 & $\mathrm{~mm}$ \\
\hline Inlet valve lift & $L_{\mathrm{IV}}$ & 9.3 & $\mathrm{~mm}$ \\
\hline Exhaust valve lift & $L_{\mathbf{E V}}$ & 9.3 & $\mathrm{~mm}$ \\
\hline Inlet valve open & $\theta_{\text {IVO }}$ & $=-410$ & ${ }^{\circ}$ ATDC \\
\hline Inlet valve close & $\theta_{\text {IVC }}$ & $=-146$ & ${ }^{\circ} \mathrm{ATDC}$ \\
\hline Exhaust valve open & $\theta_{\text {EVO }}$ & $=+130$ & ${ }^{\circ} \mathrm{ATDC}$ \\
\hline Exhaust valve close & $\theta_{\text {EVC }}$ & $=+390$ & ${ }^{\circ} \mathrm{ATDC}$ \\
\hline Volume at top dead center & $V_{\mathrm{TDC}}$ & $=105$ & $\mathrm{cc}$ \\
\hline Volume at bottom dead center & $V_{\mathrm{BDC}}$ & $=825$ & $\mathrm{cc}$ \\
\hline Volume at inlet valve close & $V_{\text {IVC }}$ & 780 & $\mathrm{cc}$ \\
\hline Total crevice volume & $V_{\text {cr }}$ & 3.5 & $\mathrm{cc}$ \\
\hline Valve displacement volume & $V_{\mathrm{VAL}}$ & 13.6 & $\mathrm{cc}$ \\
\hline
\end{tabular}

\section{TABLE 2}

Engine Operating Conditions

(a) Fixed parameters

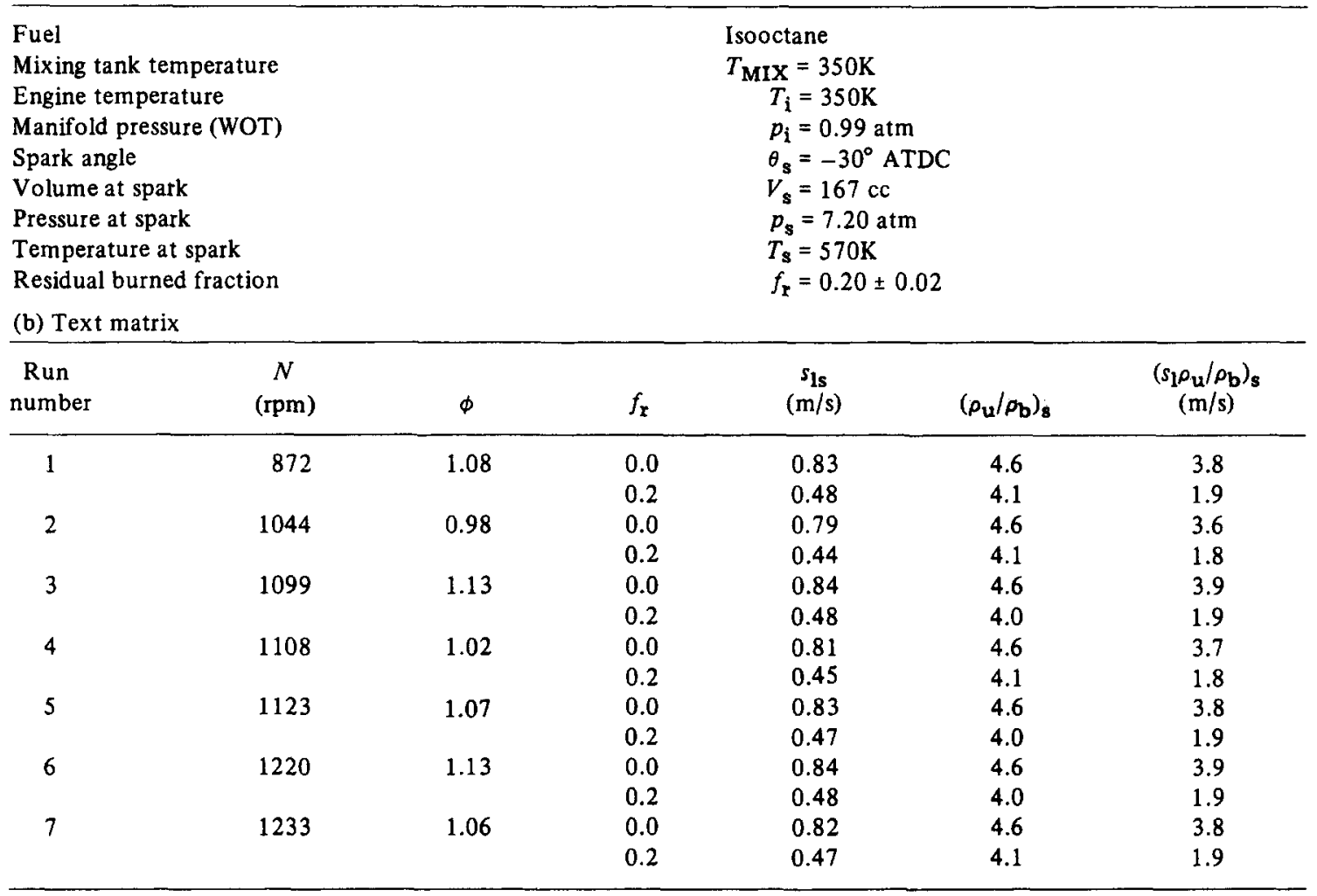




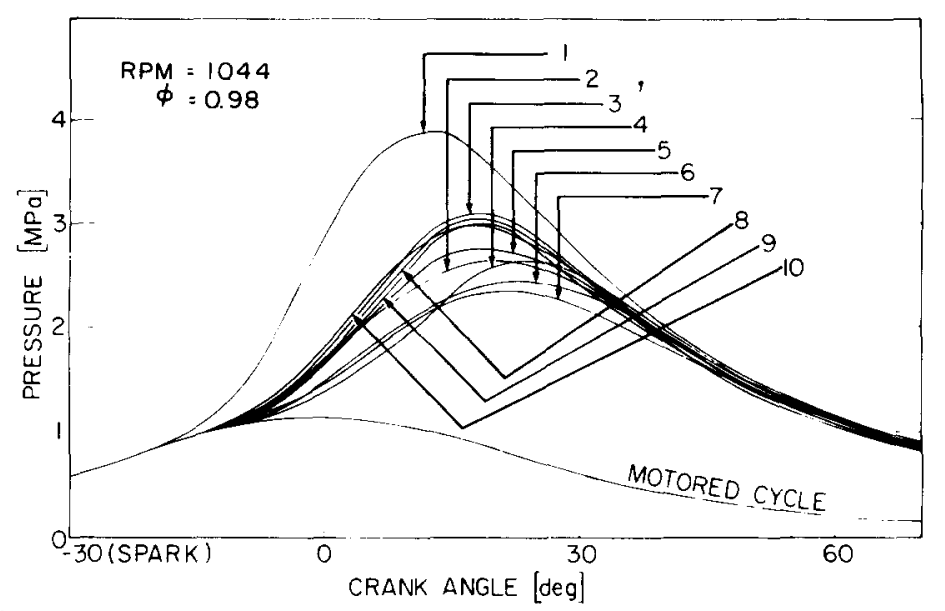

Fig. 2. Typical sequence of pressure versus crank angle traces from the M.I.T. quartz piston engine.

obtained just prior to switching on the ignition. It provided both a useful reference curve and a check on the absolute calibration of the pressure transducer. Due to the absence of residual burned gases in the charge, the first cycle has a higher peak pressure and a shorter burning time than the subsequent cycles. Using the pressure ratio between the first and subsequent cycles and the thermodynamic analysis discussed later, the residual burned gas fraction $f_{\mathrm{r}}$ was determined within an experimental error of $\pm 10 \%$ to be 0.20 for all engine operating conditions and showed no cycle-to-cycle fluctuations.

Although the cycles subsequent to the first show substantial cycle-to-cycle fluctuations in pressure, there is no evidence that the second cycle differs significantly from those following it, indicating that relaxation to steady state operation occurs within one cycle. In a normal engine, cycleto-cycle fluctuations of the magnitude shown in Fig. 2 would be considered excessive. However, in the present case, they provided useful information about the causes of this phenomenon which will be discussed later.

A typical photographic record of a propagating flame is shown in Fig. 3. The spark is at the right edge of the field of view and the flame is propagating from right to left. The engine operating conditions for this cycle are given at the top of the figure and the pressure record is shown by curve 10 in Fig. 2. The crank angle $\theta$ and the ratio of the pressure $p$ to the corresponding motored pres- sure $p_{\mathrm{m}}$ are given below each frame. The interval between frames is 1.9 crank angle degrees or 0.30 ms. Note that the spark occurred at a crank angle of $-30^{\circ}$ ATDC and that the first five frames during which the image was too weak to record satisfactorily have been omitted. It can be seen that the edge of the flame is reasonably well defined and similar in appearance to the edge of a cloud. It can also be seen that during the first few frames in which the flame front is clearly visible, the increase in pressure above the motored pressure is very small. Thus, optical observations provide a much better indication of the progress of flame propagation at early times than pressure measurements.

\section{ANALYSIS OF EXPERIMENTAL DATA}

To determine the interrelations between pressure rise, burning rate, and flame propagation rate, it is necessary to extract from the experimental data both the mass fraction of burned gas and the fraction of volume enflamed as functions of crank angle. The methods used for this purpose and some empirical correlations found are discussed in this section.

\subsection{Mass Fraction Burned}

The thermodynamic analysis used to calculate the mass fraction of burned gas from the pressure records is an improved version of that developed by 

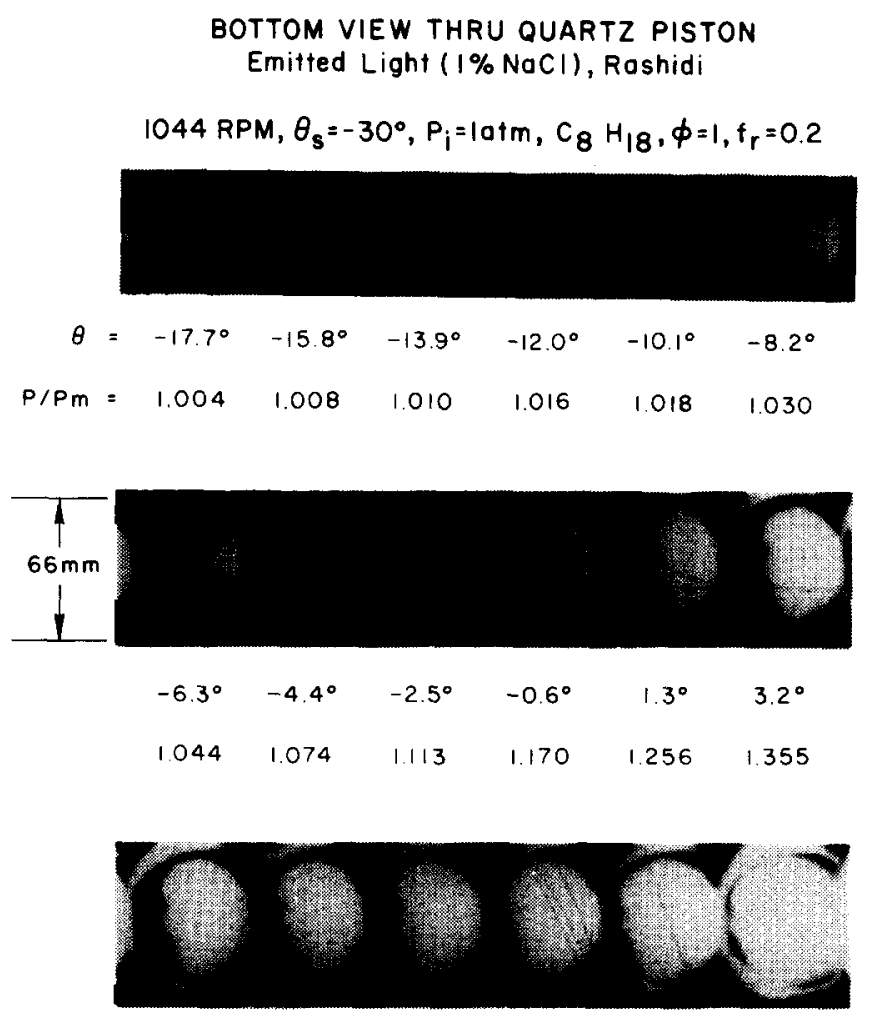

$$
\begin{array}{llllll}
5.1^{\circ} & 7.0^{\circ} & 8.9^{\circ} & 10.8^{\circ} & 12.7^{\circ} & 14.6^{\circ} \\
1.413 & 1.553 & 1.716 & 1.881 & 2.065 & 2.256
\end{array}
$$

Fig. 3. Typical high-speed motion picture record of flame propagation in the M.I.T. quartz piston engine (cycle 10 of Fig. 2).

Lavoie et al. [20] and includes the important effect of gases cycled in and out of crevices. At every instant, this analysis involves the following basic assumptions: (i) the total mass in the combustion chamber can be divided into a mass fraction burned, a mass fraction unburned, and a negligible fraction of reacting gas; (ii) the pressure is spatially uniform throughout the combustion chamber and the crevices; (iii) both unburned and burned gases obey the ideal gas equation of state; (iv) the composition of unburned gases is frozen; (v) the composition of burned gases is that of chemical equilibrium; (vi) unburned gases in the combustion chamber (excluding crevices and boundary layers) are compressed isentropically; (vii) gases in the crevices are at the wall temperature; and (viii) unburned gases flowing from the crevices into an enflamed region of the combustion chamber burn instantly.
The equations for volume and mass in the combustion chamber (excluding crevices) are

$V=V_{\mathrm{u}}+V_{\mathrm{b}}$

and

$m=m_{\mathrm{u}}+m_{\mathrm{b}}$,

where the subscripts $u$ and $b$ denote unburned gas and burned gas, respectively. The mass and volume burned fractions are defined by

$x_{\mathrm{b}}=m_{\mathrm{b}} / m$

and

$y_{\mathrm{b}}=V_{\mathrm{b}} / V$, 


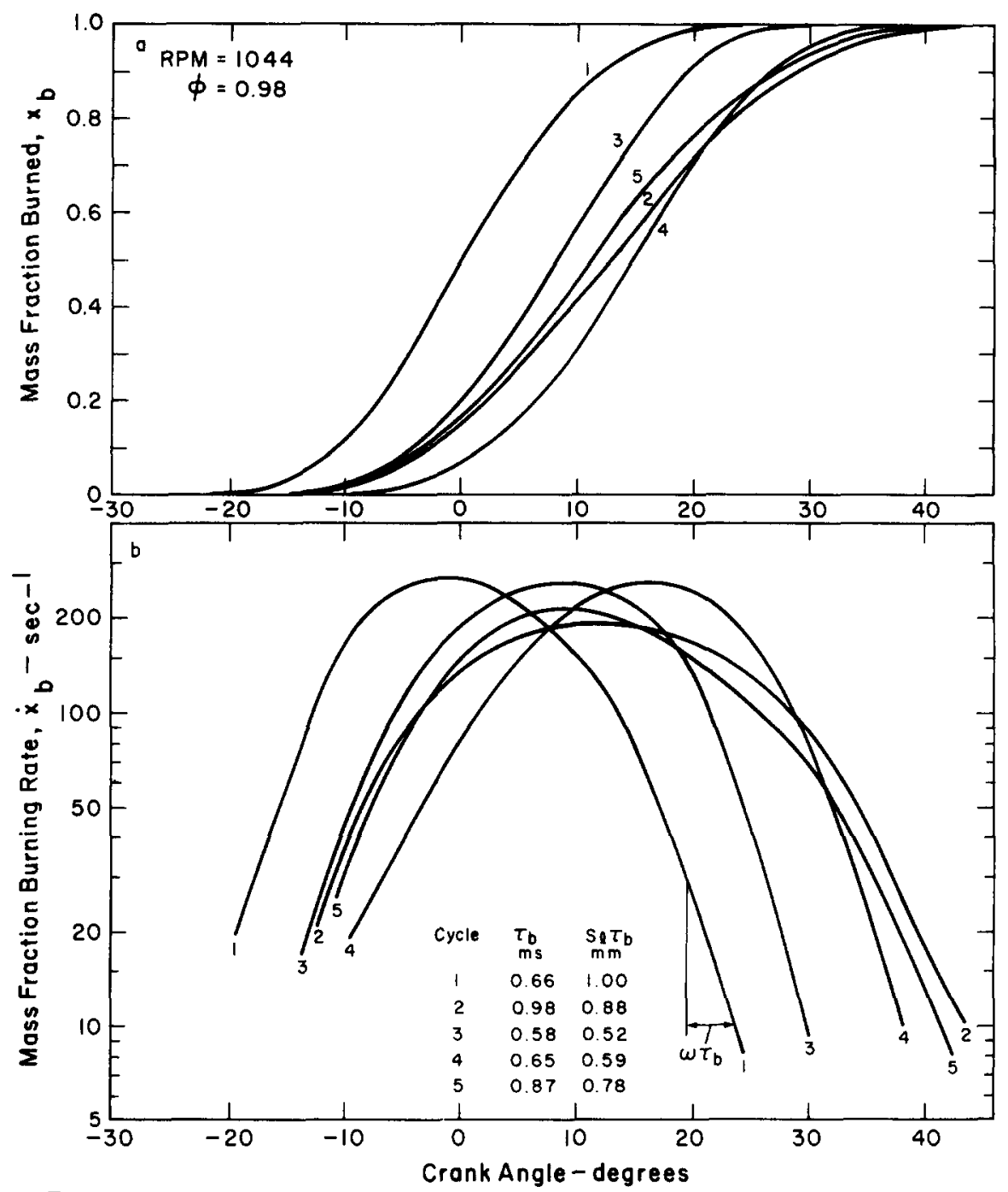

Fig. 4. (a) Typical mass fraction burned curves from the pressure records for cycles 1-5 of Fig. 2. (b) Mass fraction burning rate curves obtained by taking the time derivative of the curves in (a).

respectively, and the mean burned and unburned gas densities by

$\rho_{\mathrm{b}}=m_{\mathrm{b}} / V_{\mathrm{b}}$

and

$\rho_{\mathbf{u}}=m_{\mathbf{u}} / V_{\mathbf{u}}$.

Heat loss was estimated using the correlation of Woschni [21] and mass loss to the crankcase was estimated using the equations for inviscid flow through the piston ring gap. Using the measurements of pressure as a function of crank angle and the data on engine geometry and operating conditions summarized in Tables 1 and 2, the energy balance equation for the combustion chamber was solved to yield the mass fraction burned and all the other relevant thermodynamic properties of the gas mixture at each instant. It is of interest to note that the effect of gases cycled in and out of the crevice volume was considerably larger than that of either heat or mass loss.

The results of applying the thermodynamic analysis to the smoothed pressure curves for the first 5 cycles in Fig. 2 are plotted in Fig. 4. Part (a) shows the mass fraction burned $x_{b}$ and part (b) the corresponding mass fraction burning rate $\dot{x}_{\mathbf{b}}$ as 


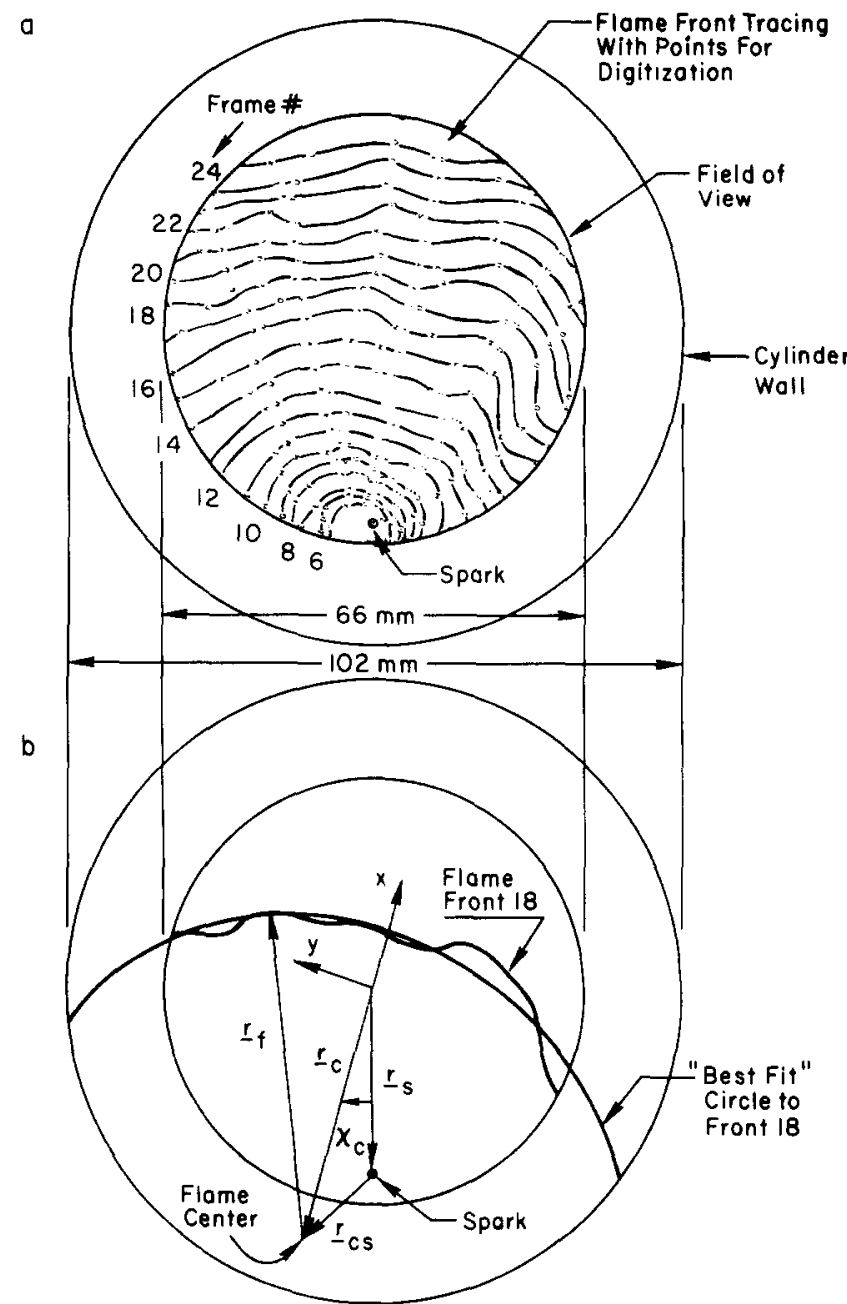

Fig. 5. (a) Superimposed tracings of the successive flame fronts shown in Fig. 3. (b) Illustration showing "best fit" circle to flame front 18 .

functions of crank angle. For burned mass fractions less than 0.002 the burning rates were too small to be measurable.

As previously noted, the charge for the first cycle contains no burned residual gas, and this is the cause of the significantly smaller "ignition delay" for this cycle. Subsequent cycles show substantial cycle-to-cycle fluctuations in both magnitude and shape of the burning rate curves, but again there is no evidence that the second cycle differs significantly from those following it. The final burning rates can be approximated by exponential decays having time constants $\tau_{\mathrm{b}}$ varying from 0.6 to $1.0 \mathrm{~ms}$, as given in the figure. Also given are the corresponding characteristic lengths $s_{1} \tau_{b}$ obtained by multiplying $\tau_{b}$ by the laminar flame speed. Geometrical data to be discussed later show that the exponential burning phase occurs after all the charge in the combustion chamber has been fully entrained by the flame front. This strongly suggests the existence of unburned gas pockets entrained behind the flame front.

\subsection{Flame Radius and Center}

Using motion picture records of the type shown in Fig. 3, Rashidi has made contour plots of the flame front profiles in successive frames for over 100 individual cycles covering the range of operating conditions given in Table 2. A plot of this type, made from the photographs in Fig. 3, is shown in Fig. 5a. It can be seen that due to the 
limited field of view a substantial part of the flame front profile was not observable.

To determine the effective flame center and radius, the method of least squares has been used to obtain "best fit" circles to the observable portion of the flame fronts. In making the fits, the radius of the circle and the position of the center are the parameters to be determined and the "best fit" circle is required to enclose the same area as the observed flame front. The coordinate system employed and an example of such a fit are shown in Fig. 5b. Figure 6 shows the "best fit" flame radius $r_{f}$ and center radius $r_{c}$ as a function of crank angle for the first 5 cycles of Fig. 2. The points (cycle numbers) correspond to individual frames of the motion pictures. The "edge of field" line shows the radius beyond which a portion of the flame front is out of the field of view. For flame radii less than $\sim 4 \mathrm{~mm}$ the images were too weak for the edge to be clearly defined, while for flame radii greater than $\sim 30 \mathrm{~mm}$ the angle sub. tended by the observed flame front was too small to permit accurate determination of the radial position of the center.

It can be seen in Fig. 6a that the expansion speed of the flame front increases substantially during

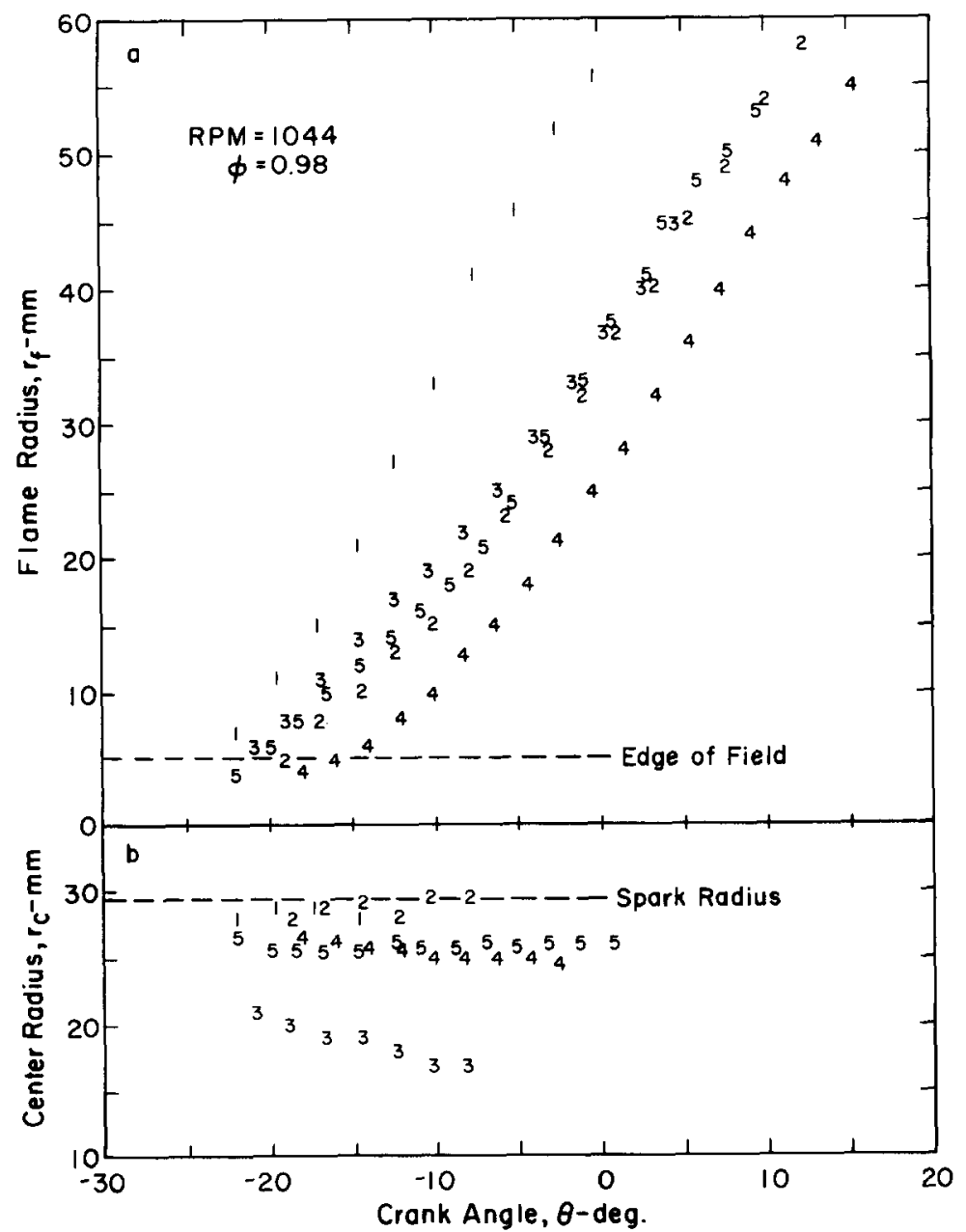

Fig. 6. (a) Typical plot of "best fit" flame radius $r_{f}$ as a function crank angle $\theta$ for cycles 1-5 of Fig. 2. The points (cycle numbers) correspond to individual frames of the motion picture record. The "edge-of-field" line shows the radius beyond which only part of the flame front is visible. (b) Plot of corresponding flame center radius $r_{c}$. 
the first $20 \mathrm{~mm}$ of flame travel, approaching an approximately constant value with relatively little cycle-to-cycle variation (see also Section 4.2). On the other hand, the times required to reach the final speed show substantial cycle-to-cycle variations which are strongly correlated with the mass fraction-burned curves in Fig. 4. It can also be seen in Fig. 6b that there can be substantial radial displacements of the flame center from the spark location, most of which occur before the flame has grown sufficiently to be clearly visible. Although this displacement shows large cycle-to-cycle variations, correlations with the curves in Fig. $6 \mathrm{~b}$ or Fig. 4 are less apparent.

The motion of the flame center during flame propagation is further illustrated in Fig. 7a, where a typical plot of the displacement $r_{\mathrm{cs}}$ of the flame center from the spark is shown as a function of flame radius $r_{f}$. The data suggest that most of the displacement occurs when the flame radius is less than $10 \mathrm{~mm}$ and that for larger radii the position of the flame center stabilizes. A characteristic flame radius required for stabilization can be defined by the equation

$l_{\mathrm{c}}=\delta_{\mathrm{c}} /\left(d r_{\mathrm{cs}} / d r_{\mathrm{f}}\right)_{\mathrm{s}}=\delta_{\mathrm{c}} /\left(u_{\mathrm{c}} / u_{\mathrm{f}}\right)_{\mathrm{s}}$

where $\delta_{c}$ is the displacement of the stable center from the spark, $\left(d r_{\mathrm{cs}} / d r_{\mathrm{f}}\right)_{\mathrm{s}}$ is the derivative of $r_{\mathrm{cs}}$ with respect to $r_{\mathrm{f}}$ at $r_{\mathrm{f}}=0$, and $\left(u_{\mathrm{c}} / u_{\mathrm{f}}\right)_{\mathrm{s}}$ is the ratio of the speed of the center to the expansion speed of the flame at $r_{\mathrm{f}}=0$. The definition of $l_{\mathrm{c}}$ is illustrated geometrically in Fig. 7a, and a plot of the displacement $\delta_{c}$ as a function of the speed ratio $\left(u_{\mathrm{c}} / u_{\mathrm{f}}\right)_{\mathrm{s}}$ is shown in Fig. $7 \mathrm{~b}$. The speed ratio was approximated by the expression $\left(u_{\mathrm{c}} / u_{\mathrm{f}}\right)_{\mathrm{s}} \cong\left(r_{\mathrm{cs}} /\right.$ $\left.r_{\mathrm{f}}\right)_{1}$, where $\left(r_{\mathrm{cs}} / r_{\mathrm{f}}\right)_{1}$ is the ratio of the flame center displacement to the flame radius for the first "best fit" circle. The value of $l_{c}$ determined by the "best" line through the data is $l_{c}=5.7 \pm 1.0$ $\mathrm{mm}$.

A rough indication of the character of the velocity field in the vicinity of the spark plug at ignition can be obtained from Fig. 8, which shows the azimuthal component $r_{\mathrm{c}} \dot{x}_{\mathrm{c}}$ of the flame center velocity plotted as a function of the radial component $-\dot{r}_{\mathbf{c}}$. The average values of the velocities for each run are shown along the axes. Large cycle-tocycle variations in both the magnitude and direc- tion of the center velocity are apparent. There is also a clear indication of an inward "squish" velocity $-\dot{r}_{\mathrm{c}} \sim 1.4 \mathrm{~m} / \mathrm{s}$ due to the boss in which the spark plug is located and a net "swirl" velocity $r_{\mathrm{c}} \dot{\chi}_{\mathbf{c}} \sim 1.0 \mathrm{~m} / \mathrm{s}$ corresponding to $\dot{\chi}_{\mathbf{c}} \sim 450 \mathrm{rpm}$. Since the inlet valve was unshrouded, the latter must be due to slight asymmetries of the intake port geometry.

\subsection{Enflamed Volume}

The flame geometry and coordinate system used to reconstruct the flame front in three dimensions are shown in Fig. 9a. It has been assumed that the geometrical characteristics of the flame front are well approximated by a spherical surface of radius $r_{\mathbf{f}}$ with its center located at the same radial and angular position as the "best fit" circle, and at the same height as the spark.

Trajectories of the flame center and of the flame fronts propagating toward the near and far walls are illustrated in Fig. 9b. Because of the limited field of view, the crank angles $\theta_{N}$ and $\theta_{F}$ at which the flame fronts reach the near and far walls had to be determined by extrapolation. Also shown in Fig. 9b is a typical gas "particle" trajectory. Due to the expansion of the gas during combustion, the unburned gas ahead of the flame front is pushed away from the front.

Some important geometrical properties of the flame are shown in Fig. 10. Part (a) shows the enflamed volume fraction $y_{\mathrm{f}}=V_{\mathrm{f}} / \pi R^{2} h$ at top center as a function of the dimensionless flame radius $\tilde{r}_{\mathrm{f}}=r_{\mathrm{f}} / R$ for various values of the dimensionless flame center radius $\tilde{r}_{\mathrm{c}}=r_{\mathrm{c}} / R$. Part (b) shows the corresponding dimensionless flame front area $a_{\mathrm{f}}=$ $A_{\mathrm{f}} / \pi R h$ as a function of $y_{\mathrm{f}}$. The effect of the flame center position on the flame front area can be clearly seen in Fig. 10b. Variations in the location of the stable flame center produce variations in the flame front area and are an important source of cycle-to-cycle variations in the burning rate.

\section{CORRELATION OF PRESSURE AND OPTICAL DATA}

To facilitate the comparison between pressure and optical observations, it is convenient to introduce several basic definitions: 

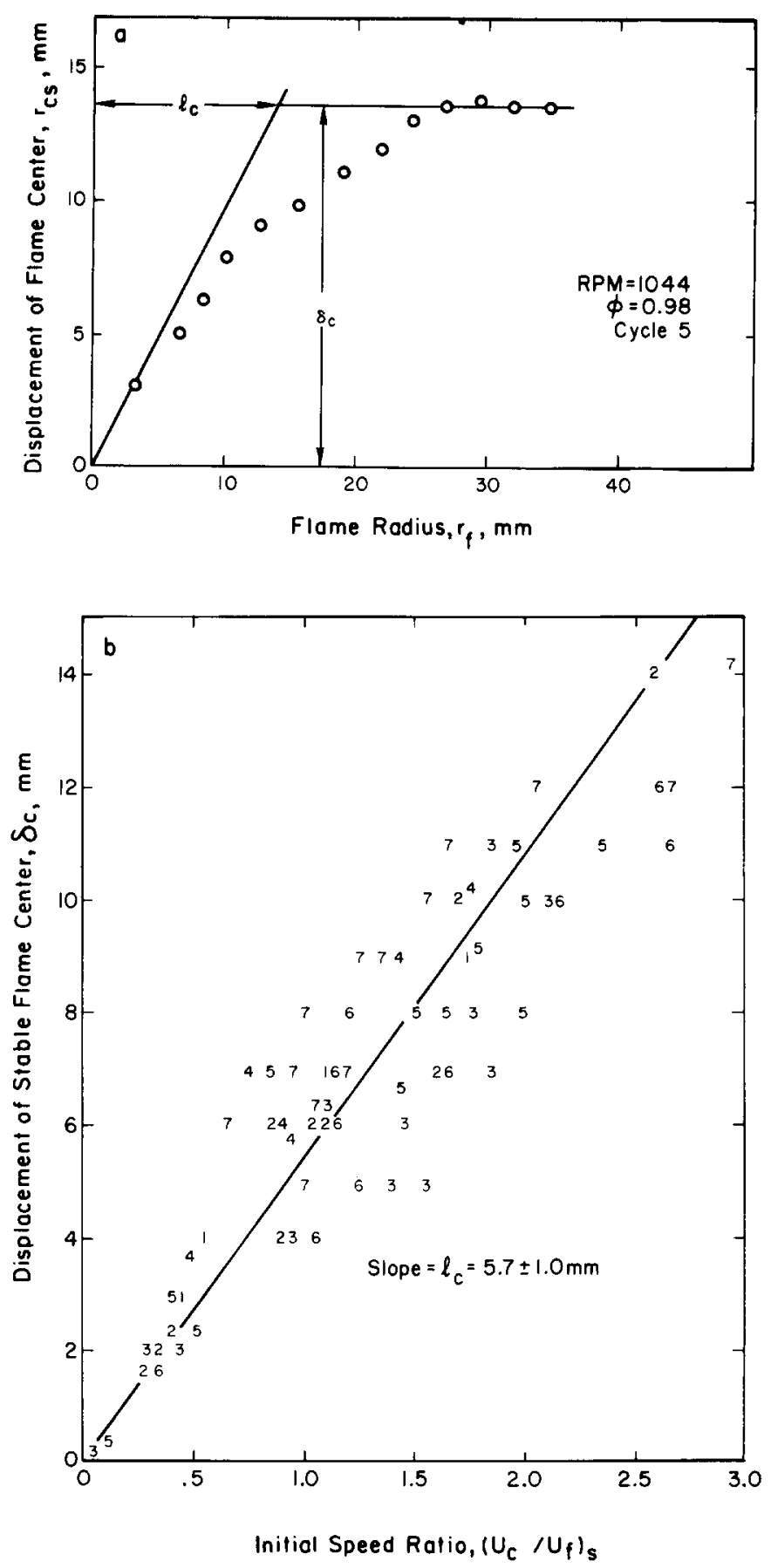

Fig. 7. (a) Plot of the displacement $r_{\mathrm{cs}}$ of the flame center from the spark location as a function of the flame radius $r_{t}$ showing the definitions of the characteristic flame radius $l_{\mathrm{c}}$ required for stabilization and the displacement $\delta_{\mathrm{c}}$ of the stable center from spark. (b) Center displacement $\delta_{c}$ as a function of ratio of the initial speed $u_{c s}$ of the center to the initial expansion speed $u_{f_{s}}=s_{1 s}\left(\rho_{u} / \rho_{b}\right)_{s}$ of the flame front. Numbers refer to runs. 


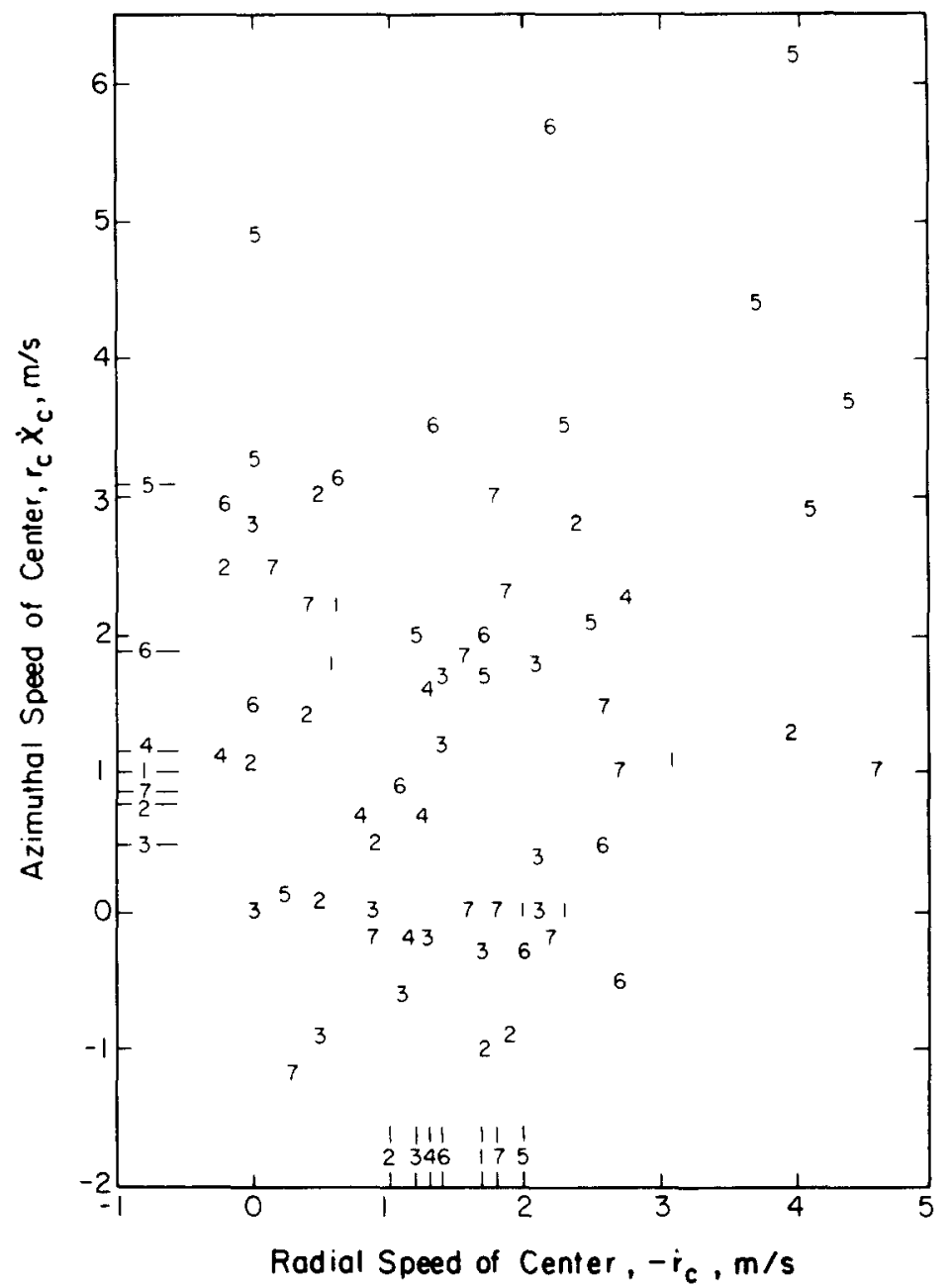

Fig. 8. Azimuthal speed of the flame center at spark $r_{c} \dot{x}_{c}$ as a function of the radial speed $-\dot{r}_{\mathbf{c}}$. Numbers refer to runs.

(i) the equivalent burned gas radius $r_{b}$, defined by the equation

$V_{\mathrm{b}}\left(r_{\mathrm{b}}, \underline{r}_{\mathrm{c}}, h\right) \equiv V_{\mathrm{b}}$,

where $h=V / A_{\mathfrak{p}}$ is the mean height of the combustion chamber, $A_{\mathfrak{p}}$ is the area of the piston, $\underline{r}_{\mathrm{c}}$ is the position of the flame center, and $r_{b}$ is the radius of an ideal spherical surface, concentric with the flame front, containing all and only the burned gases;

(ii) the equivalent spherical burning area

$A_{\mathrm{b}} \equiv \partial V_{\mathrm{b}} / \partial r_{\mathrm{b}}$ (iii) the equivalent laminar burning area

$$
A_{1} \equiv \dot{m}_{\mathrm{b}} / \rho_{\mathrm{u}} s_{1},
$$

where $s_{1}$ is the laminar burning speed;

(iv) the mean burned gas expansion speed

$$
\begin{aligned}
u_{\mathrm{b}} & =\left(\partial V_{\mathrm{b}} / \partial t\right)_{\mathrm{h}} / A_{\mathrm{b}} \\
& =\dot{r}_{\mathrm{b}}+\dot{r}_{\mathrm{c}} \partial V_{\mathrm{b}} / \partial \underline{r}_{\mathbf{c}},
\end{aligned}
$$

where subscript h denotes fixed clearance height;

(v) the burning speed 


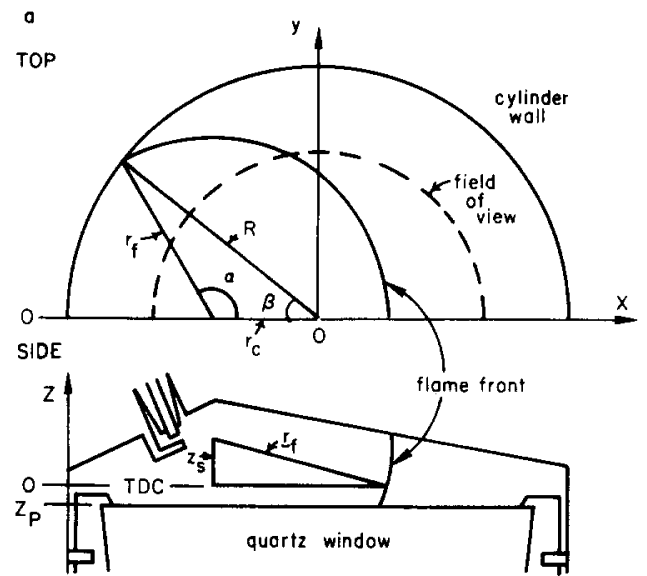

b

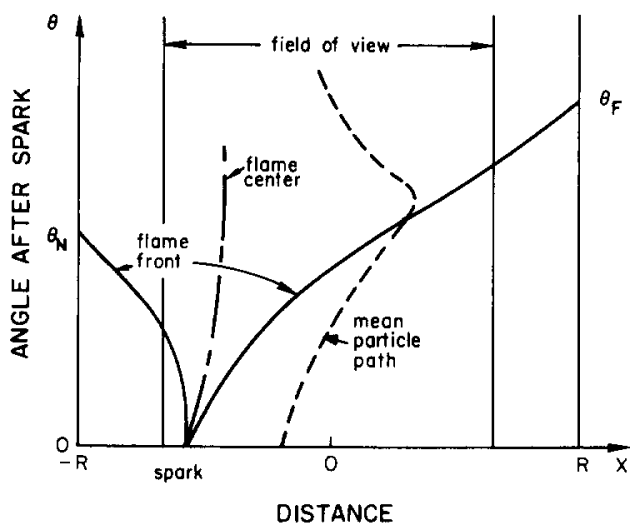

Fig. 9. (a) Schematic diagram of combustion chamber geometry and spherical flame front. (b) Angle versus distance plot showing qualitative trajectories for flame center, flame fronts, and a gas particle.

(vi) the mean flame front expansion speed

$$
\begin{aligned}
u_{\mathrm{f}} & \equiv \dot{A}_{\mathrm{c}} / L_{\mathrm{c}} \\
& =\dot{r}_{\mathrm{f}}+\left(\dot{r}_{\mathrm{c}} \partial A_{\mathrm{c}} / \partial r_{\mathrm{c}}+\dot{\chi}_{\mathrm{c}} \partial A_{\mathrm{c}} / \partial \chi_{\mathrm{c}}\right) / L_{\mathrm{c}},
\end{aligned}
$$

where $A_{\mathrm{c}}=A_{\mathrm{c}}\left(r_{\mathrm{f}}, r_{\mathrm{c}}, \chi_{\mathrm{c}}\right)$ is the "shadow" area enclosed by the "best fit" circles through the leading edge of the flame front and $L_{\mathrm{c}}=\partial A_{\mathrm{c}} / \partial r_{\mathrm{f}}$ is the arc length of the "best fit" circles (Figure $5 \mathrm{~b}$ ).

It follows from Eqs. (10) and (12) that

$$
s_{\mathrm{b}} A_{\mathrm{b}}=s_{1} A_{1}
$$

It also follows from the mass conservation equation that

$\dot{m}=-\dot{m}_{\mathrm{uk}}-\dot{m}_{\mathrm{bk}}$ and from Eqs. (1), (2), (5), (6), (11), and (12) that

$$
\begin{aligned}
s_{\mathrm{b}} \frac{m}{\rho_{\mathrm{b}} V} & =u_{\mathrm{b}}+\frac{V_{\mathrm{b}}}{A_{\mathrm{b}}}\left(1-\frac{V_{\mathrm{b}}}{V}\right)\left\{\left(\frac{\dot{h}_{\mathrm{b}}}{h_{\mathrm{b}}}-\frac{\dot{h}_{\mathrm{u}}}{h_{\mathrm{u}}}\right)\right. \\
& \left.+\left(\frac{\dot{\rho}_{\mathrm{b}}}{\rho_{\mathrm{b}}}-\frac{\dot{\rho}_{\mathrm{u}}}{\rho_{\mathrm{u}}}\right)+\left(\frac{\dot{m}_{\mathrm{bk}}}{m_{\mathrm{b}}}-\frac{\dot{m}_{\mathrm{uk}}}{m_{\mathrm{u}}}\right)\right\},
\end{aligned}
$$

where $m_{\mathrm{bk}}$ and $m_{\mathrm{uk}}$ are the mass flow rates of burned and unburned gas out of the combustion chamber, $h_{\mathrm{b}}=V_{\mathrm{b}} / A_{\mathrm{pb}}$ and $h_{\mathrm{u}}=V_{\mathrm{u}} / A_{\mathrm{pu}}$ are equivalent mean heights of burned and unburned gases, $A_{\mathrm{pb}}$ is the area of the piston face delineated by the equivalent burned spherical surface, and $A_{\mathrm{pu}}=A_{\mathrm{p}}-A_{\mathrm{pb}}$. Under almost all conditions of practical interest, the second term on the righthand side of Eq. (16) is negligible and it is a good approximation to set

$u_{\mathrm{b}} \cong\left(m / \rho_{\mathrm{b}} V\right) s_{\mathrm{b}}$.

Moreover, it follows from Eqs. (1)-(6) that

$\frac{m}{\rho_{\mathrm{b}} V}=\frac{\rho_{\mathrm{u}}}{\rho_{\mathrm{b}}}\left(1-y_{\mathrm{b}}\right)+y_{\mathrm{b}}$.

Note that as $y_{\mathrm{b}} \rightarrow 0, m / \rho_{\mathrm{b}} V$ approaches the expansion ratio $\rho_{\mathbf{u}} / \rho_{\mathbf{b}}$.

Plots of $m / \rho_{\mathrm{b}} V$ and $\rho_{\mathrm{u}} / \rho_{\mathrm{b}}$ as functions of $y_{\mathrm{b}}$ are shown in Fig. 11a for a spark advance $\theta_{s}=$ $-30^{\circ}$ and residual burned gas fractions $f_{\mathbf{r}}=0$ and 0.2 . A plot of the useful relation

$x_{\mathrm{b}}=\left(1+\frac{\rho_{\mathrm{u}}}{\rho_{\mathrm{b}}}\left(\frac{1}{y_{\mathrm{b}}}-1\right)\right)^{-1}$

obtained from Eqs. (1)-(6) is shown in Fig. 11b. The values of $\rho_{\mathfrak{u}} / \rho_{\mathrm{b}}$ were obtained from the thermodynamic analysis.

It can be seen in Fig. 11a that following an initial sharp drop due to compression by the piston, $\rho_{\mathrm{u}} / \rho_{\mathrm{b}}$ remains nearly constant over most of the burning range. This is an extremely useful property and simplifies the approximate analysis of combustion in spark ignition engines.

In particular, combining Eqs. (18) and (19) and 

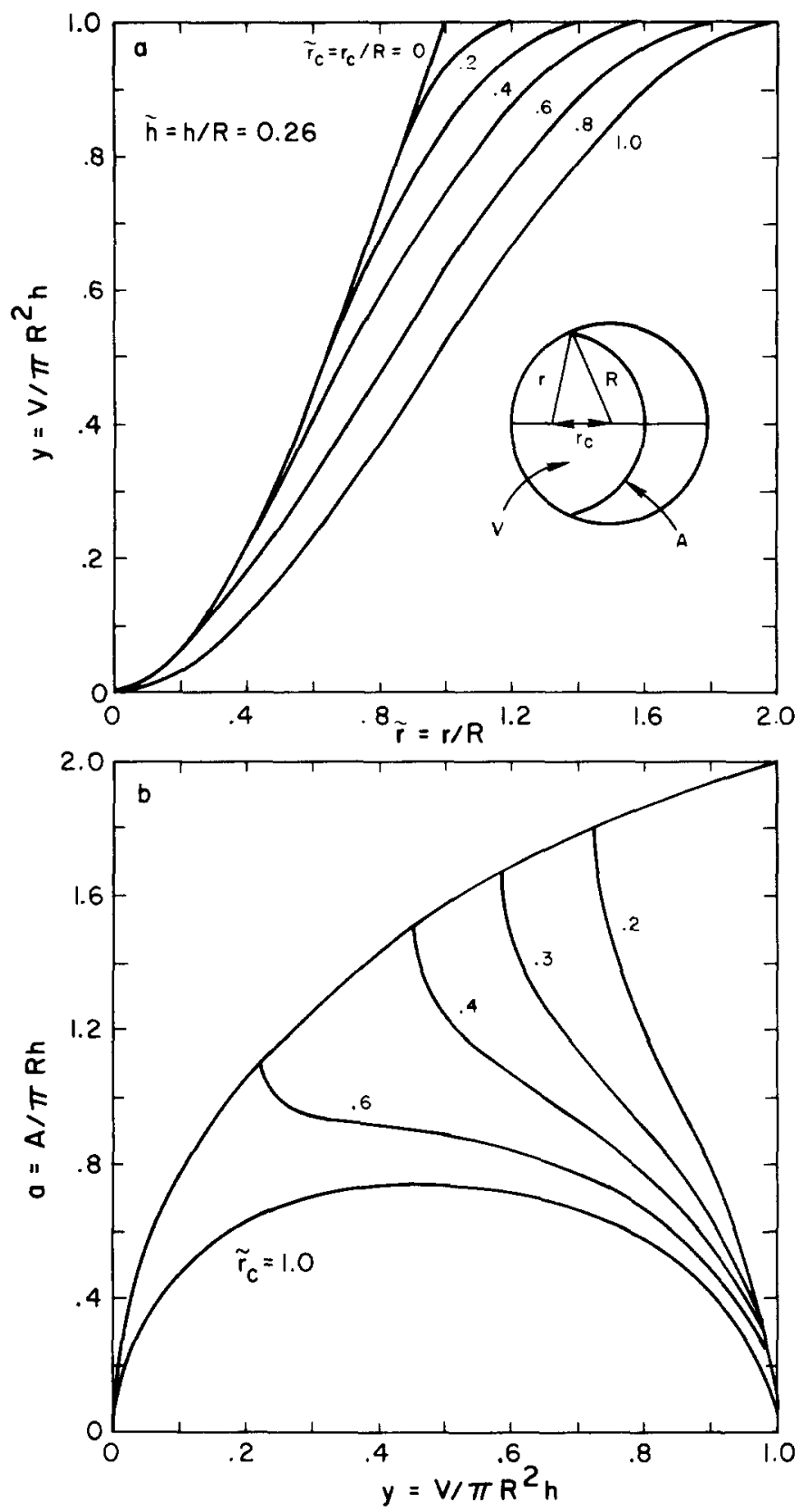

Fig. 10. (a) Dimensionless flame volume versus flame radius plots for various center locations. (b) Dimensionless flame area versus volume plots for various center locations. The dummy geometrical variables $r, A, a, V$, and $y$ can take both the subscripts $f$ and $b$.

using the relation

$\rho_{\mathrm{u}}{ }^{\circ} / \rho_{\mathrm{s}}^{\circ}=\left(p / p_{\mathrm{s}}\right)^{1 / \gamma_{\mathrm{u}}}$

for isentropic compression of the unburned gas outside the thermal boundary layer, we obtain

$$
\begin{aligned}
x_{\mathrm{b}}= & \left(\left(\rho_{\mathrm{s}}{ }^{\circ} V / \rho_{\mathrm{s}} V_{\mathrm{s}}\right)\left(m_{\mathrm{s}} \rho_{\mathrm{u}} / m \rho_{\mathrm{u}}{ }^{\circ}\right)\right. \\
& \left.\times\left(p / p_{\mathrm{s}}\right)^{1 / \gamma_{\mathrm{u}}}-1\right) /\left(\rho_{\mathrm{u}} / \rho_{\mathrm{b}}-1\right),
\end{aligned}
$$



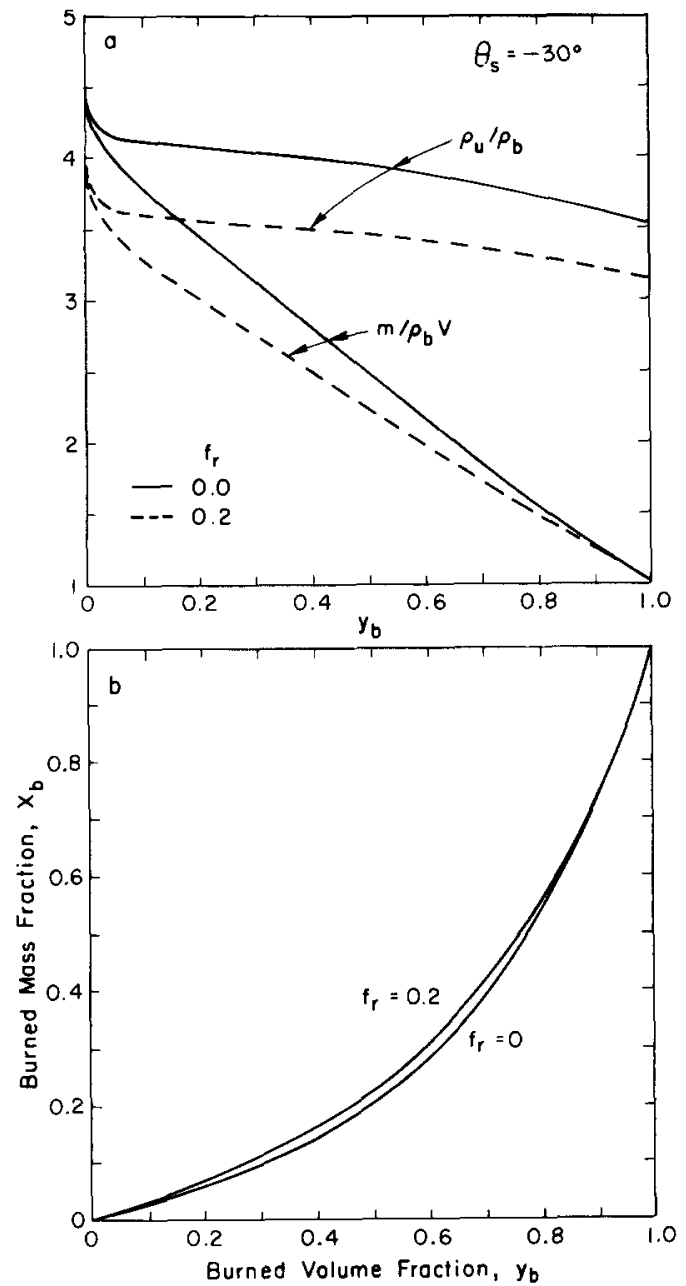

Fig. 11. (a) $\rho_{\mathfrak{u}} / \rho_{\mathbf{b}}$ and $m / \rho_{\mathbf{b}} V$ as a function of volume fraction of burned gas $y_{b}$ for residual burned gas fractions $f_{Y}=0$ and 0.2 . (b) Burned gas mass fraction $x_{b}$ as a function of burned gas volume fraction for residual burned gas mass fractions $f_{\mathrm{r}}=0$ and 0.2 .

where $\gamma_{\mathbf{u}}=c_{\mathrm{pu}} / c_{\mathrm{vu}}$ is the specific heat ratio for the unburned gas, the subscript $s$ denotes conditions at spark, and the superscript o denotes conditions outside the thermal boundary layer. If we now assume that for $\left(p-p_{\mathrm{s}}\right) / p_{\mathrm{s}} \ll 1$, heat and mass losses from the combustion chamber volume $V$ (excluding crevices) are the same under firing and motoring conditions, then Eq. (21a) reduces to

$x_{\mathrm{b}}=\left(\left(p / p_{\mathrm{m}}\right)^{\left.1 / \gamma_{\mathrm{u}}-1\right) /\left(\rho_{\mathrm{u}} / \rho_{\mathrm{b}}-1\right),}\right.$

where $p / p_{\mathrm{m}}$ is the ratio of the firing and motoring pressures. The advantages of Eq. (21b) are that it is independent of crank angle, it does not require modeling of either heat or mass losses from the combustion chamber, and it is relatively insensitive to the value of $\gamma_{\mathbf{u}}$ and the density ratio $\rho_{\mathfrak{u}} / \rho_{\mathbf{b}}$. Eq. (21b) has been used to determine the initial values of $x_{\mathrm{b}}$.

\subsection{Flame Geometry}

The burned gas volume fraction $y_{b}$ and the enflamed volume fraction $y_{f}$ are shown as functions of the flame radius $r_{\mathrm{f}}$ in Fig. (12a) for the first 5 cycles of Fig. 2. The corresponding dimensionless laminar burning area $a_{1}=A_{1} / \pi R h$ and flame area $a_{\mathrm{f}}=A_{\mathrm{f}} / \pi R h$ are shown in Fig. $12 \mathrm{~b}$. Discontinuities in the derivative of $a_{f}$ occur at the points where the flame front touches first the piston face and then the near wall. It can be seen in Fig. 12a that during the rapid flame propagation phase $\left(y_{f} \tilde{>}\right.$ 0.2 ), the value of $y_{\mathrm{f}}$ is significantly greater than $y_{\mathrm{b}}$. It can also be seen in Fig. $12 \mathrm{~b}$ that during this phase the laminar area exceeds the flame front area by almost a factor of 10 . These observations together with the assumption (see Section 3.1) that the reacting mass fraction is negligible imply the existence of substantial pockets of unburned gas behind the leading edge of the visible flame.

A plot of $r_{f}$ as a function of $r_{b}$ is shown in Fig. 13a. The difference $\left(r_{f}-r_{b}\right)$ is shown in Fig. $13 b$. The burned gas radius $r_{b}$ was determined from the burned gas volume fraction $y_{\mathrm{b}}$ using the measured values of the flame center radius $r_{c}$ and the curves in Fig. 10a. It can be seen that as $r_{b} \rightarrow 0, r_{f} \rightarrow r_{b}$. This suggests that entrainment of unburned gas behind the flame front is small during the early development of the flame. On the other hand, for $r_{\mathrm{b}} \sim 30 \mathrm{~mm},\left(r_{\mathrm{f}}-r_{\mathrm{b}}\right) \cong 6 \mathrm{~mm}$ and is approximately constant. This suggests that the entrainment and combustion rates have approximately balanced in a quasi-steady rapid propagation phase in which a substantial amount of unburned gases is steadily present behind the flame front.

An interesting comparison suggested by the data in Figs. 12 and 13 is shown in Fig. 14a, where the differences $\left(A_{1}-A_{\mathrm{f}}\right)$ and $\left(V_{\mathrm{f}}-V_{\mathrm{b}}\right)$ are plotted on a logarithmic scale as functions of $r_{f}$. It can be seen that the two sets of points are remarkably 


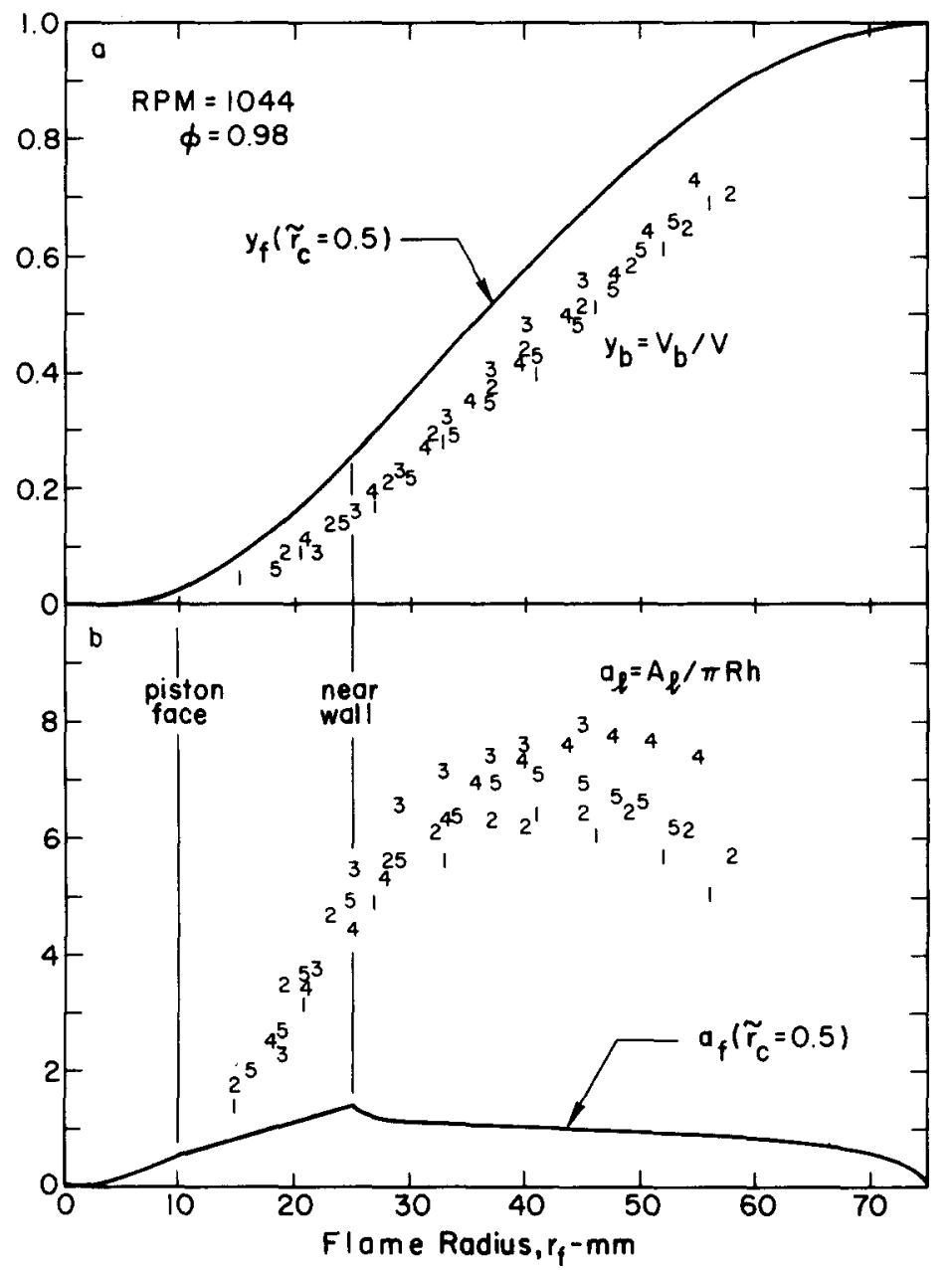

Fig. 12. (a) Comparison of burned gas volume fraction $y_{b}$ for cycles 1-5 of Fig. 2 and enflamed volume fraction $y_{f}$ as a function of flame radius $r_{f}$. A mean value of 0.5 was assumed for $\tilde{r}_{\mathrm{c}}=r_{\mathrm{c}} / R$ in calculating $y_{\mathrm{f}}$. (b) Comparison of the dimensionless laminar burning area $a_{1}$ and the dimensionless flame area $a_{\mathrm{f}}$. Note that discontinuities in the derivative of $a_{\mathrm{f}}$ occur when the flame front impinges on the piston face and the near wall. 


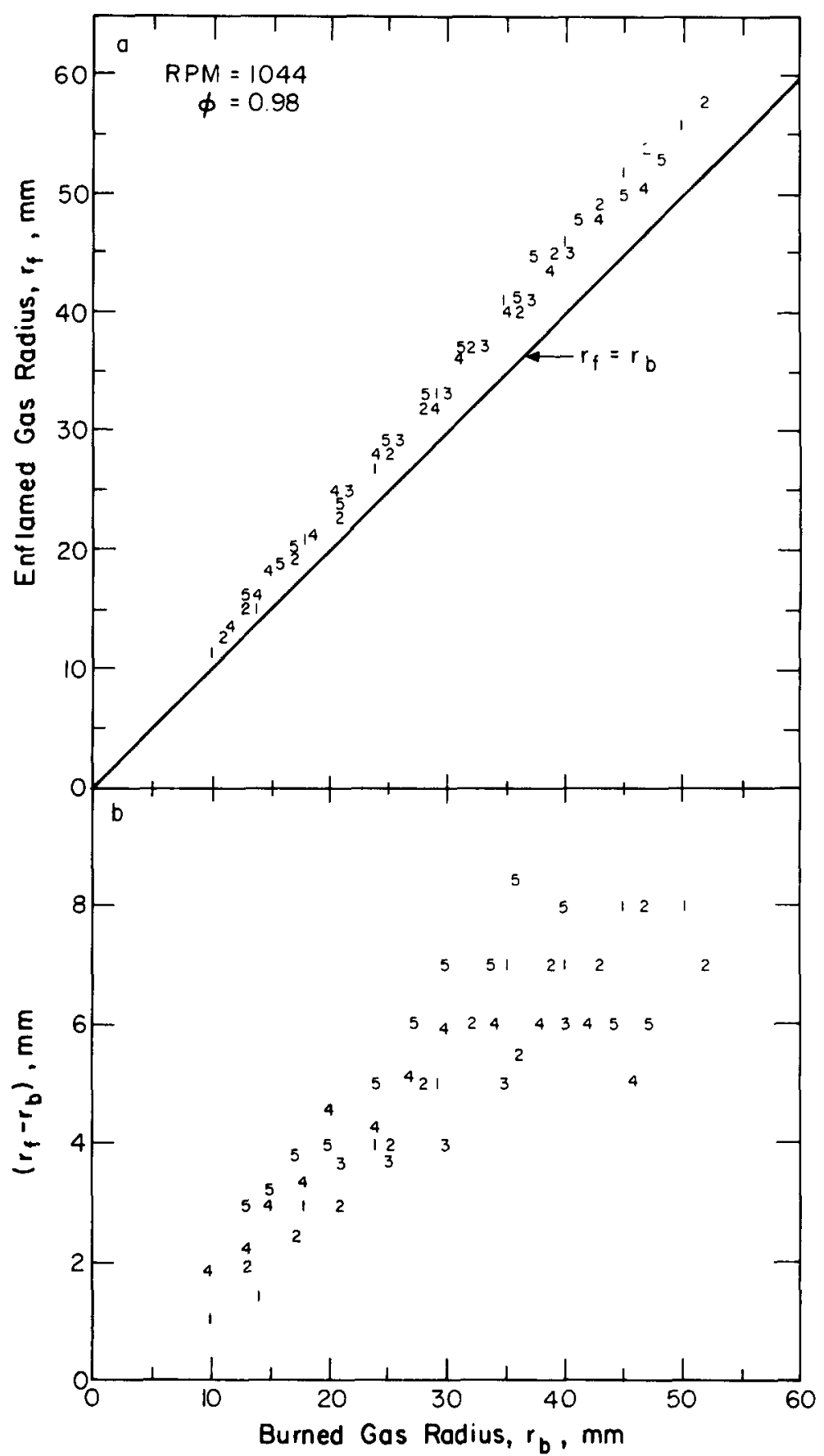

Fig. 13. (a) Flame radius $r_{f}$ as a function of burned gas radius $r_{b}$ for cycles 1-5 of Fig. 2. (b) Difference $r_{f}-r_{b}$ as a function $r_{b}$. 
TURBULENT FLAMES IN SPARK IGNITION ENGINES

233

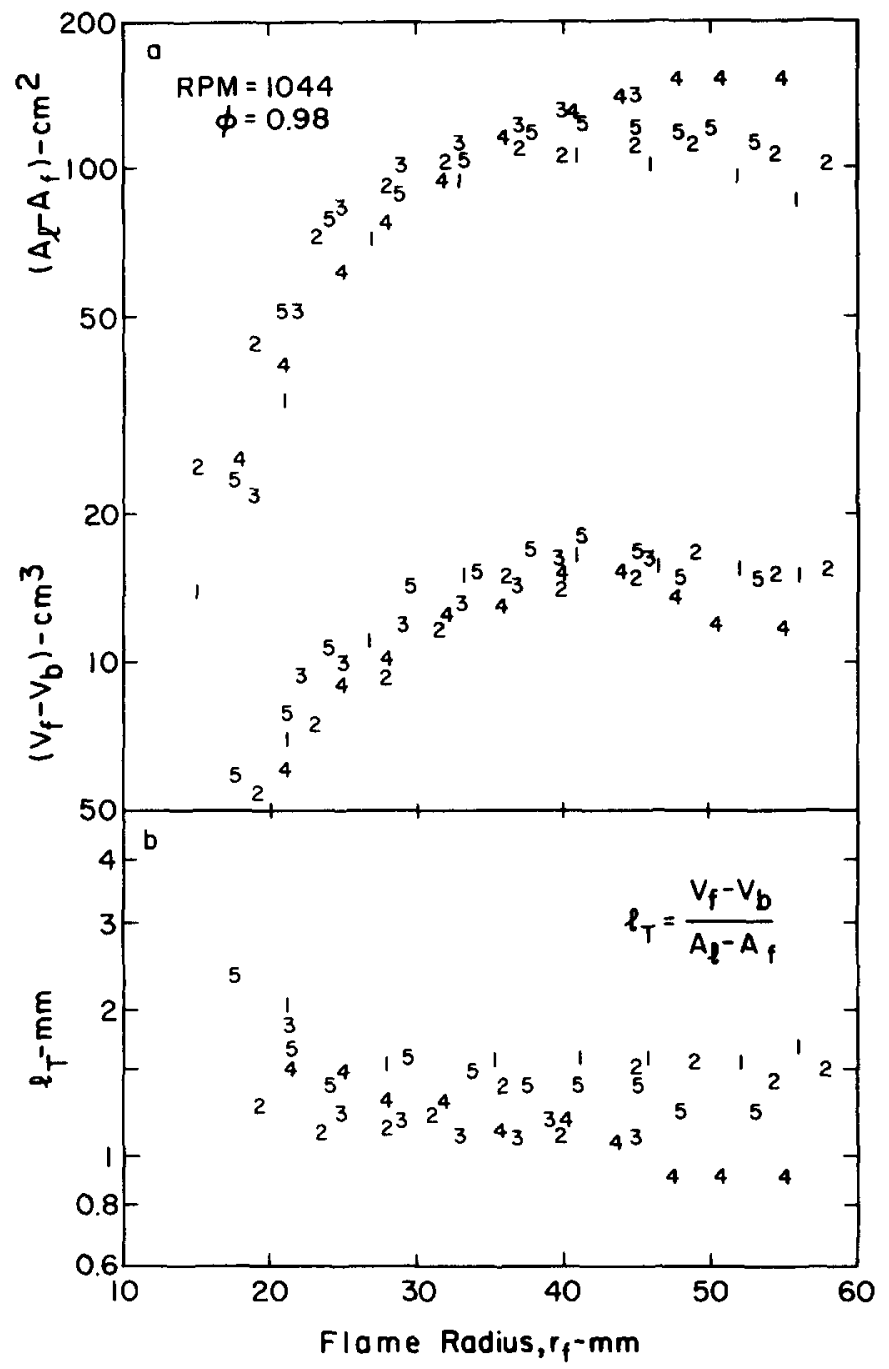

Fig. 14. (a) Plots of $\left(A_{1}-A_{f}\right)$ and $\left(V_{f}-V_{b}\right)$ as functions of $r_{f}$ for cycles 1-5 of Fig. 2. (b) Corresponding characteristic length $l_{\mathrm{T}}=\left(V_{\mathrm{f}}-V_{\mathrm{b}}\right) /\left(A_{1}-A_{\mathrm{f}}\right)$. 
similar in shape, suggesting that their ratio should be approximately constant. This ratio $l_{\mathrm{T}}=\left(V_{\mathrm{f}}\right.$ $\left.V_{\mathrm{b}}\right) /\left(A_{1}-A_{\mathrm{f}}\right)$, which has the dimensions of a length, is plotted in Fig. 14b. Although there is considerable cycle-to-cycle scatter, the points for any one cycle are quite consistent and suggest a slight decrease in $l_{\mathrm{T}}$ with increasing $r_{\mathrm{f}}$. How much of the cycle-to-cycle scatter is intrinsic to $l_{\mathbf{T}}$ and how much is due to measurement errors is not clear. The relatively small difference $\left(V_{f}-V_{b}\right)$ is very sensitive both to errors in the measurements of $V_{\mathrm{f}}$ and $V_{\mathrm{b}}$ individually and to the synchronization of optical and pressure data. Nevertheless the measurements show $l_{\mathrm{T}}$ to be approximately 1.3 $\mathrm{mm}$ in the range $r_{\mathrm{f}}=20-55 \mathrm{~mm}$, corresponding to $y_{\mathrm{r}}=0.20-0.85$.

\subsection{Characteristic Speeds}

The flame front expansion speeds $u_{\mathrm{f}}$ calculated from Eq. (13) are shown as functions of the flame radius $r_{f}$ by the upper set of points in Fig. 15a for the first 5 cycles of Fig. 2. Also shown are the cor. responding burning speeds $s_{\mathrm{b}}$ obtained from Eq. (17) using the approximation $u_{\mathrm{b}} \cong u_{\mathrm{f}}$ (justified by the data in Fig. 13a) and the laminar burning speeds $s_{1}$ measured by Metghalchi and Keck [22] for isooctane/air mixtures with residual burned gas fractions $f_{\mathrm{r}}=0$ and 0.2 . The difference between $u_{\mathrm{b}} \cong u_{\mathrm{f}}$ and $s_{\mathrm{b}}$ is the unburned gas speed $u_{\mathrm{g}}$ just ahead of the flame front. Note that the ratio $u_{\mathrm{f}} / s_{\mathrm{b}}$ decreases monotonically from a value equal to the expansion ratio $\rho_{\mathrm{u}} / \rho_{\mathrm{b}}$ at $\theta_{\mathrm{s}}$ to a value of unity as the flame front approaches the far wall.

It can be seen that although the values of $s_{b}$ are approximately the same for all cycles, the values of $u_{\mathrm{f}}$ for the first cycle are somewhat higher than those for subsequent cycles. This is primarily due to the large value of the expansion ratio for the first cycle. It can also be seen that $s_{\mathrm{b}}$ increases from a value close to $s_{1}$ to a value of order 10 times $s_{1}$ as $r_{f}$ increases from 0 to $50 \mathrm{~mm}$. For $r_{f} \tilde{s}$ $30 \mathrm{~mm}, s_{\mathbf{b}}$ is roughly proportional to $\sqrt{\rho_{\mathbf{u}}}$.

Fig. $15 \mathrm{~b}$ shows the ratio $s_{\mathrm{b}} / s_{1}$ as a function of $r_{\mathrm{f}}$. By definition this ratio is also equal to the ratio $A_{1} / A_{\mathrm{b}}$ of the laminar burning area to the spherical burning area. Note that the ratio $s_{\mathrm{b}} / s_{1}$ for large $r_{\mathrm{f}}$ is significantly lower for the first cycle than for the following cycles due to the higher laminar burning speed of the charge for the first cycle. Also note that for $r_{f}>30 \mathrm{~mm}, s_{b} / s_{1}$ is constant within the scatter of the data. Since for isentropic compression of the unburned gas $s_{1} \cong s_{1 s}\left(\rho_{u} / \rho_{s}\right)^{0.4}$, this is consistent with the observation previously made that $s_{\mathrm{b}}$ is proportional to $\sqrt{\rho_{\mathrm{u}}}$.

The values of $u_{\mathrm{f}}{ }^{*}, s_{\mathrm{b}}{ }^{*}, u_{\mathrm{T}}{ }^{*}=s_{\mathrm{b}}{ }^{*}-s_{1}{ }^{*}$, and $r_{\mathrm{c}}{ }^{*}$ at the angle $\theta^{*}$ of maximum burning rate $\left(r_{\mathrm{f}}{ }^{*} \cong\right.$ $45 \mathrm{~mm}$ ) are summarized in Table 3 for all runs listed in Table 2. Also given are values of the parameters $u_{\mathrm{fs}}$ and $\tau_{\mathrm{fs}}$ obtained by making a least squares fit of the equation

$u_{\mathrm{f}}=u_{\mathrm{fs}}+r_{\mathrm{f}} / \tau_{\mathrm{fs}}$

to the measured expansions speed for $r_{\mathrm{f}} \tilde{<} 15 \mathrm{~mm}$, where $u_{\mathrm{fs}}$ is an extrapolated expansion speed at spark time and $\tau_{\mathbf{f s}}$ a characteristic time describing the initial rapid increase in the expansion speed $u_{\mathrm{f}}$. For each entry of Table 3, the first line gives the value for the first cycle and the second line the average value for all subsequent cycles along with the standard deviation of the cycle-to-cycle dispersion.

All of the quantities tabulated show cycle-tocycle dispersion of the order of $\pm 10 \%$ or greater. Part of this is undoubtedly due to measurement errors, but most of it is felt to reflect the actual dispersion. The values of $u_{\mathrm{f}}{ }^{*}, s_{\mathrm{b}}{ }^{*}$, and $u_{\mathrm{T}}{ }^{*}$ appear to increase with engine speed, while those for $r_{\mathrm{c}}{ }^{*}$, $u_{\mathrm{fs}}$, and $\tau_{\mathrm{fs}}$ show no statistically significant trends. The only quantities for which the first cycle values are significantly different from the averages for the subsequent cycles are $u_{\mathrm{f}}{ }^{*}$ and $u_{\mathrm{fs}}$. In the case of $u_{\mathrm{f}}{ }^{*}$, the difference can be attributed largely to the difference in $\rho_{\mathrm{u}} / \rho_{\mathrm{b}}$ as previously noted. In the case of $u_{\mathrm{fs}}$, the difference can be attributed to the difference in the laminar expansion speed $s_{1}\left(\rho_{\mathbf{u}} / \rho_{\mathrm{b}}\right)$ for the first and subsequent cycles. The measured values agree well with the calculated values of 3.8 and $1.9 \mathrm{~m} / \mathrm{s}$ given in Table 2 .

\subsection{Burning and Propagation Angles}

The most common method used to characterize mass fraction-burned curves of the type shown in Fig. $4 \mathrm{a}$ is to introduce a set of burning angles. One 


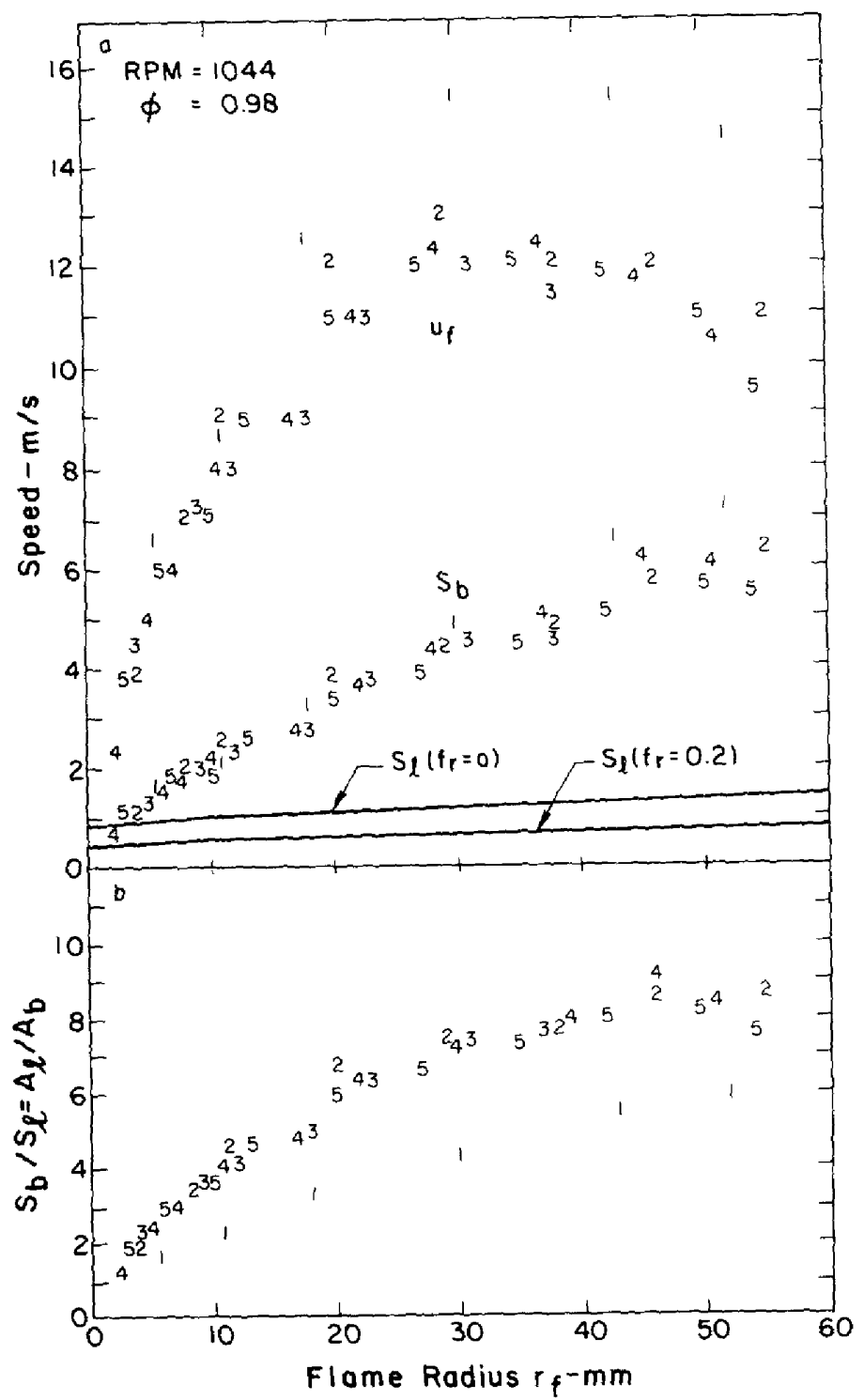

Fig. 15. (a) Plots of the expansion speed $u_{f}$ and the corresponding burning speed $s_{b}$ as a function of flame radius $r_{f}$ for cycles 1-5 of Fig. 2. Also shown is the laminar burning speed $s_{1}$ for 0 and $20 \%$ residual burned gas fractions. (b) Corresponding ratio $s_{b} / s_{l}=$ $A \sqrt{ } / A_{\mathbf{b}}$. 
TABLE 3

Characteristic Velocity Parametersa

\begin{tabular}{|c|c|c|c|c|c|c|c|c|}
\hline Run no. & 1 & 2 & 3 & 4 & 5 & 6 & 7 & \\
\hline$N(\mathrm{rpm})$ & 872 & 1044 & 1099 & 1108 & 1123 & 1220 & 1233 & \\
\hline$\phi$ & 1.09 & 0.98 & 1.14 & 1.02 & 1.08 & 1.13 & 1.07 & Run ave. \\
\hline \multirow[t]{2}{*}{$u_{\mathrm{fs}}(\mathrm{m} / \mathrm{s})$} & $3.7^{b}$ & 2.8 & 3.7 & 2.7 & 3.3 & 4.0 & 4.2 & $3.5(0.6)$ \\
\hline & $2.2(0.6)^{c}$ & $1.5(0.9)$ & $2.3(0.7)$ & $1.8(0.8)$ & $2.7(0.8)$ & $2.3(0.5)$ & $1.8(0.6)$ & $2.1(0.4)$ \\
\hline \multirow{2}{*}{$\tau_{\mathrm{fs}}(\mathrm{ms})$} & 1.7 & 1.3 & 1.9 & 1.2 & 1.9 & 1.4 & 1.8 & $1.6(0.3)$ \\
\hline & $2.2(0.3)$ & $1.6(0.3)$ & $1.4(0.2)$ & $1.4(0.2)$ & $1.8(0.5)$ & $1.4(0.2)$ & $1.4(0.2)$ & $1.6(0.3)$ \\
\hline \multirow{2}{*}{$u_{\mathrm{f}}^{*}(\mathrm{~m} / \mathrm{s})$} & 12.0 & 14.1 & 13.9 & 15.2 & 15.9 & 15.8 & 14.4 & $14.5(1.3)$ \\
\hline & $10.4(0.8)$ & $10.9(1.0)$ & $13.0(1.4)$ & $13.0(1.0)$ & $12.7(1.0)$ & $13.3(1.5)$ & $13.6(1.4)$ & $12.4(1.2)$ \\
\hline \multirow[t]{2}{*}{$s_{\mathbf{b}} *(\mathrm{~m} / \mathrm{s})$} & 5.5 & 6.4 & 6.3 & 6.9 & 7.2 & 7.2 & 6.5 & $6.6(0.6)$ \\
\hline & $5.2(0.4)$ & $5.5(0.5)$ & $6.5(0.7)$ & $6.5(0.5)$ & $6.3(0.5)$ & $6.6(0.8)$ & $6.8(0.7)$ & $6.2(0.6)$ \\
\hline \multirow[t]{2}{*}{$u_{T}{ }^{*}(\mathrm{~m} / \mathrm{s})$} & 4.6 & 5.3 & 5.2 & 5.8 & 6.1 & 6.1 & 5.4 & $5.6(0.5)$ \\
\hline & $4.5(0.4)$ & $4.8(0.5)$ & $5.8(0.7)$ & $5.8(0.5)$ & $5.6(0.5)$ & $5.9(0.8)$ & $6.1(0.7)$ & $5.5(0.6)$ \\
\hline \multirow[t]{2}{*}{$r_{c}{ }^{*}(\mathrm{~mm})$} & 27 & 29 & 29 & 24 & 30 & 30 & 23 & $27(3)$ \\
\hline & $25(3)$ & $26(3)$ & $27(3)$ & $27(3)$ & $26(3)$ & $27(3)$ & $23(3)$ & $26(2)$ \\
\hline
\end{tabular}

$a$ Asterisks indicate values at maximum burning rate $x_{\mathbf{b}}$.

$b$ Numbers in first row following a parameter are for first cycle.

c Numbers in second row following a parameter are averages excluding first cycle; numbers in parentheses are standard deviations of points from averages.

way of defining these angles is shown graphically in Fig. 16. The fast burning angle $\theta_{B}$ may be defined as the angle required for a line drawn tangent to the mass fraction burned curve at the angle of maximum slope $\theta^{*}$ to rise from $x_{\mathrm{b}}=0$ to $x_{\mathrm{b}}=1$.
The burning delay angle $\theta_{\mathbf{D}}$ is then the difference between the angle at which the same line intersects $x_{\mathrm{b}}=0$ and the spark angle. The total burning angle is $\theta_{\mathbf{T}}=\theta_{\mathbf{D}}+\theta_{\mathbf{B}}$.

Flame radius curves of the type shown in Fig. 6

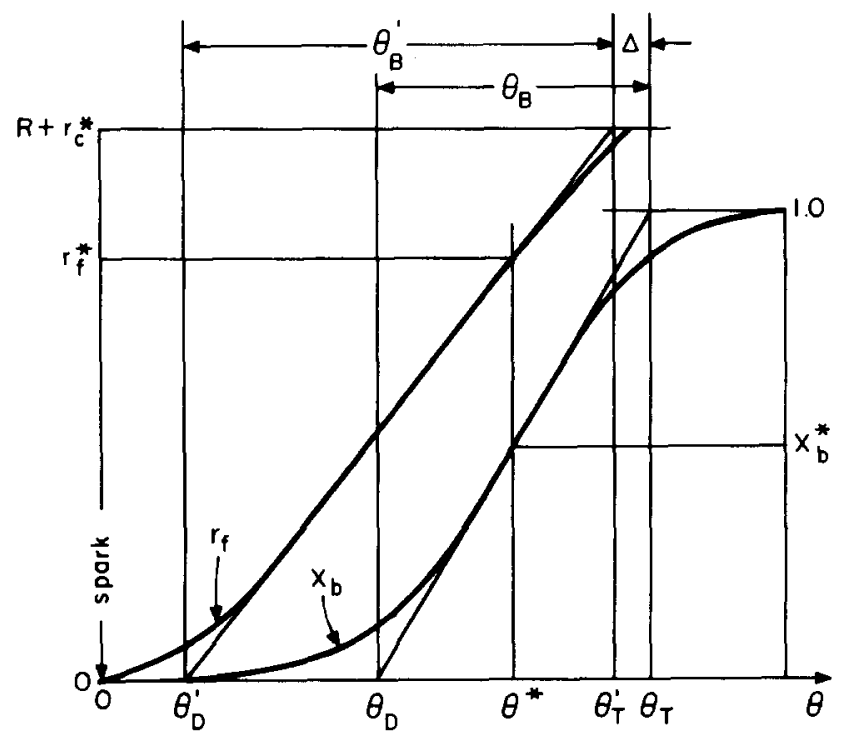

Fig. 16. Plots of $r_{f}$ and $x_{\mathrm{b}}$ versus $\theta$ showing the definitions of characteristic burning and propagation angles. 
can be characterized in a similar manner by a complementary set of angles $\theta_{\mathbf{D}}{ }^{\prime}, \theta_{\mathbf{B}}{ }^{\prime}$, and $\theta_{\mathbf{T}}{ }^{\prime}$. These angles are also shown graphically in Fig. 16. In this case, the fast propagation angle $\theta_{\mathbf{B}}{ }^{\prime}$ is defined as the angle required for a line drawn tangent to the flame radius curve at the angle of maximum burning rate $\theta^{*}$ to rise from $r_{\mathrm{f}}=0$ to $r_{\mathrm{c}}=R+r_{\mathrm{c}}{ }^{*}$. The propagation delay angle $\theta_{\mathbf{D}}{ }^{\prime}$ is the difference between the angle at which the same line intersects $r_{\mathrm{f}}=0$ and the spark angle. The total propagation angle is $\theta_{\mathbf{T}}{ }^{\prime}=\theta_{\mathbf{D}}{ }^{\prime}+\theta_{\mathbf{B}}{ }^{\prime}$.

It follows from these definitions that

$\theta_{\mathbf{B}}=\omega / \dot{x}_{\mathbf{b}}^{*}$

$\theta_{\mathrm{B}}{ }^{\prime}=\omega\left(R+r_{\mathrm{c}}{ }^{*}\right) / \dot{r}_{\mathrm{f}}^{*}$,

$\theta_{\mathrm{T}}=\theta^{*}+\omega\left(1-x_{\mathrm{b}} *\right) / \dot{x}_{\mathrm{b}} *$

$\theta_{\mathrm{T}}{ }^{\prime}=\theta^{*}+\omega\left(R+r_{\mathrm{c}}-r_{\mathrm{f}}^{*}\right) / \dot{r}_{\mathrm{f}}^{*}$

where $\omega[\mathrm{deg} / \mathrm{s}]=6 N[\mathrm{rpm}]$. Near top dead center, $\dot{V} \cong 0$ and $\dot{r}_{\mathrm{c}} \cong 0$, so that

$\dot{y}_{\mathrm{b}} \cong A_{\mathrm{b}} \dot{r}_{\mathrm{b}} / V$.

If it is also assumed, in agreement with the data in Fig. 13 , that $\dot{r}_{\mathrm{f}}{ }^{*} \cong \dot{r}_{\mathrm{b}}{ }^{*}$, then Eq. (27) can be combined with Eqs. (23)-(26) to obtain the relations

$\theta_{\mathrm{B}}{ }^{\prime}=\theta_{\mathrm{B}}\left(\frac{\left(R+r_{\mathrm{c}}\right) A_{\mathrm{b}}}{V}\right)^{*}\left(\frac{d x_{\mathrm{b}}}{d y_{\mathrm{b}}}\right)^{*}$

and

$$
\begin{aligned}
\theta_{\mathrm{T}}-\theta_{\mathrm{T}}{ }^{\prime}= & \theta_{\mathrm{B}}\left\{1-x_{\mathrm{b}}-\left(\frac{\left(R+r_{\mathrm{c}}-r_{\mathrm{f}}\right) A_{\mathrm{b}}}{V}\right)\right. \\
& \left.\times\left(\frac{d x_{\mathrm{b}}}{d y_{\mathrm{b}}}\right)\right\}^{*} .
\end{aligned}
$$

For $\left(R+r_{\mathrm{c}}-r_{\mathrm{b}}\right)<r_{\mathrm{b}}$, which is the case at maximum burning rate,

$\left(R+r_{\mathrm{c}}-r_{\mathrm{b}}\right) A_{\mathrm{b}} \cong(\pi / 2)\left(V-V_{\mathrm{b}}\right)$,

and for $\rho_{\mathrm{u}} / \rho_{\mathrm{b}}$ approximately constant as shown in
Fig. 11a, it follows from Eq. (19) that

$\frac{d x_{\mathrm{b}}}{d y_{\mathrm{b}}} \cong \frac{\rho_{\mathrm{u}}}{\rho_{\mathrm{b}}}\left(x_{\mathrm{b}}+\left(1-x_{\mathrm{b}}\right) \frac{\rho_{\mathrm{b}}}{\rho_{\mathrm{u}}}\right)^{2}$.

Finally, substituting Eqs. (30) and (31) into Eqs. (28) and (29) yields

$$
\begin{aligned}
\theta_{\mathrm{B}}{ }^{\prime} \cong & \theta_{\mathrm{B}}\left\{\left(\frac{\left(R+r_{\mathrm{c}}\right) A_{\mathrm{b}}}{V}\right) \frac{\rho_{\mathrm{u}}}{\rho_{\mathrm{b}}}\right. \\
& \left.\times\left(x_{\mathrm{b}}+\left(1-x_{\mathrm{b}}\right) \frac{\rho_{\mathrm{b}}}{\rho_{\mathrm{u}}}\right)^{2}\right\}^{*}
\end{aligned}
$$

and

$$
\begin{aligned}
\theta_{\mathbf{T}}-\theta_{\mathbf{T}}{ }^{\prime} \cong & \theta_{\mathbf{B}}\left\{( 1 - x _ { \mathrm { b } } ) \left(1-\frac{\pi}{2}\left(x_{\mathrm{b}}+\left(1-x_{\mathrm{b}}\right)\right.\right.\right. \\
& \left.\left.\left.\times \frac{\rho_{\mathrm{b}}}{\rho_{\mathrm{u}}}\right) \frac{R+r_{\mathrm{c}}-r_{\mathrm{f}}}{R+r_{\mathrm{c}}-r_{\mathrm{b}}}\right)\right\}^{*}
\end{aligned}
$$

A plot of $\theta_{\mathbf{B}}$ as a function of $\theta_{\mathbf{B}}{ }^{\prime}$ for all cycles is shown in Fig. 17a and a plot of the ratio $\theta_{B}{ }^{\prime} / \theta_{\mathbf{B}}$ as a function of $r_{\mathrm{c}}{ }^{*}$ is shown in Fig. $17 \mathrm{~b}$. The numbers refer to runs. It can be seen that, as expected, $\theta_{\mathbf{B}}$ and $\theta_{\mathbf{B}}$ ' are strongly correlated and that the ratio $\theta_{\mathbf{B}}{ }^{\prime} / \theta_{\mathbf{B}}$ is a relatively slowly varying function of $r_{\mathrm{c}}{ }^{*}$. The curve in Fig. $17 \mathrm{~b}$ was calculated using Eq. (32) and the curves in Fig. 10b. The agreement between the calculated curves and the experimental data is well within the combined systematic and statistical uncertainties.

A plot of $\theta_{\mathbf{T}}$ as a function of $\theta_{\mathbf{T}}{ }^{\prime}$ is shown in Fig. 18. It can be seen that also $\theta_{\mathbf{T}}$ and $\theta_{\mathbf{T}}{ }^{\prime}$ are strongly correlated and that $\theta_{\mathbf{T}} \cong \theta_{\mathbf{T}}{ }^{\prime}$. The mean value of $\left(\theta_{\mathbf{T}}-\theta_{\mathbf{T}}{ }^{\prime}\right) / \theta_{\mathbf{B}}$ is 0.05 , in good agreement with the value of 0.07 calculated from Eq. (33).

A comparison of the parametric angles for the first and second cycles with the average values excluding the first cycle is given in Table 4 for all runs. Also shown are the values of $x_{b}{ }^{*}$ at the angle $\theta^{*}$ of maximum burning rate. No significant departure of the second-cycle values from the average values can be seen for any of the quantities tabulated. This indicates that relaxation to steady state operation occurred within one cycle. On the 

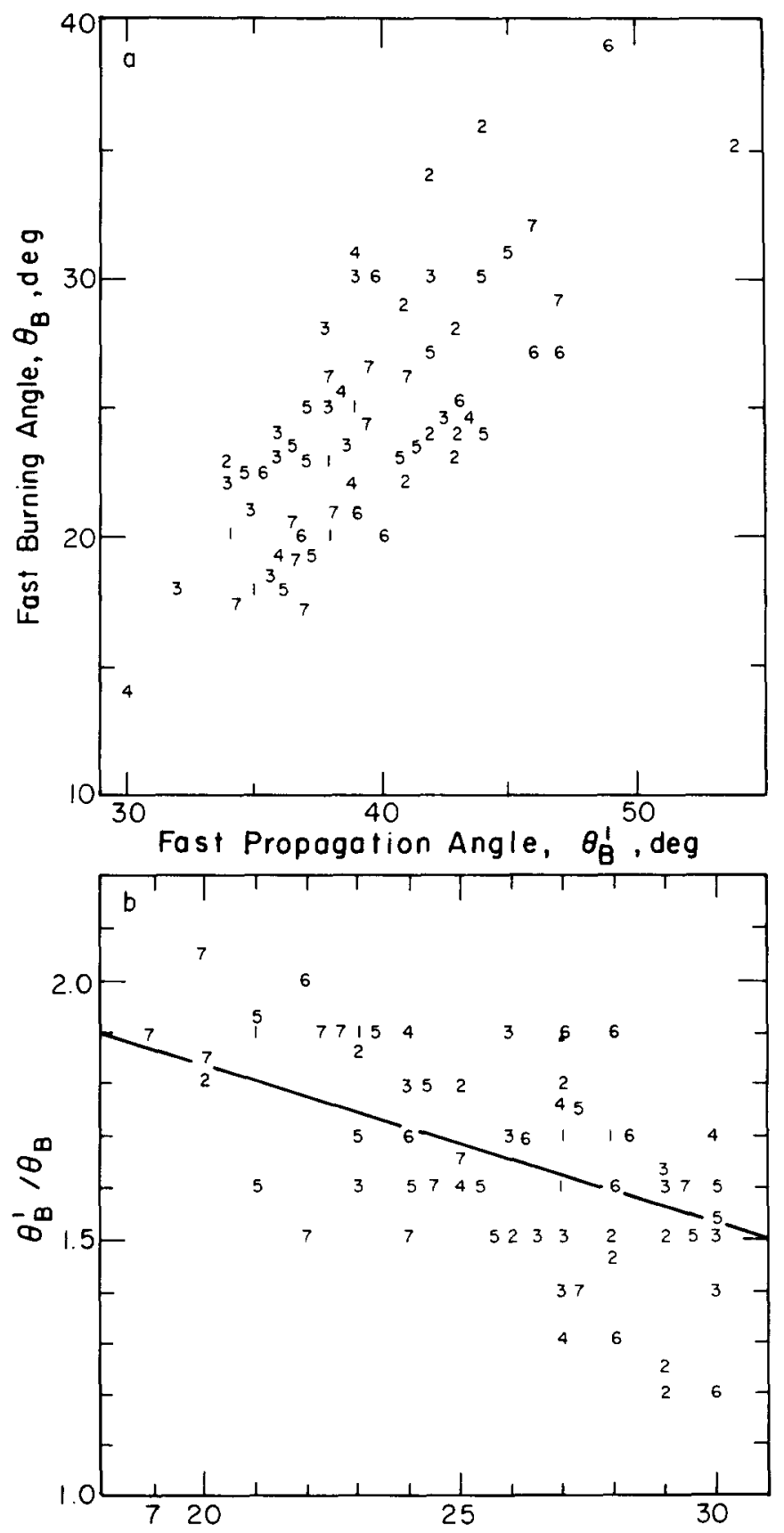

Stable Flame Center Radius, $r_{c} *, m m$

Fig. 17. (a) Fast burning angles $\theta_{\mathbf{B}}$ versus fast propagation angle $\theta_{\mathbf{B}}{ }^{\prime}$. (b) Ratio $\theta_{B}{ }^{\prime} / \theta_{B}$ as a function of flame center radius $r_{C}{ }^{*}$ at $x_{b}{ }^{*}=0.5$. Numbers refer to runs. 


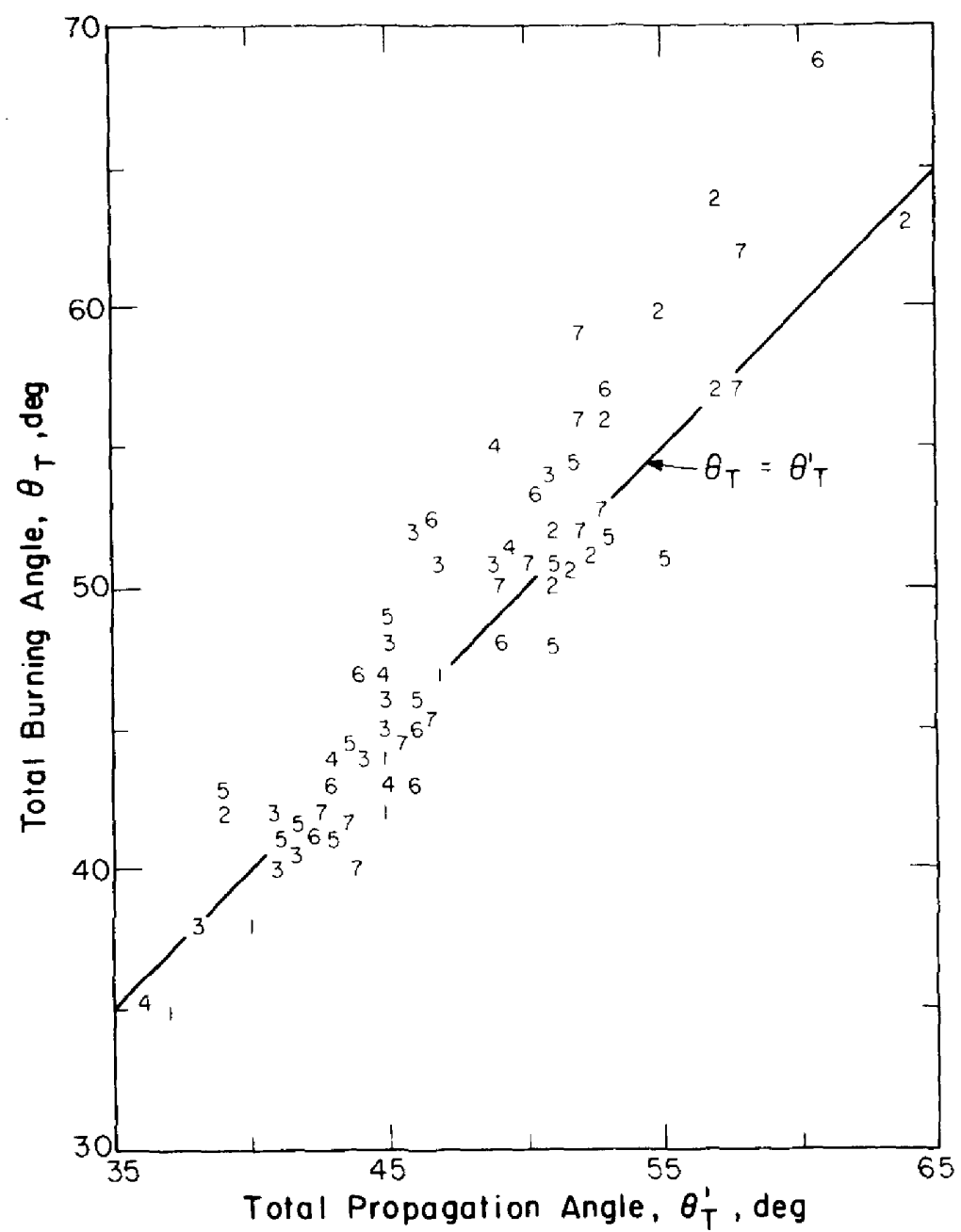

Fig. 18. Total burning angle versus total propagation angle. Numbers refer to runs.

other hand, the first cycle values of all the angles tend to be somewhat smaller than the average values, suggesting that these quantities are affected by the residual burned gas fraction. There are no significant trends of any quantity in this table with engine speed or equivalence ratio.

\section{TURBULENT BURNING EQUATIONS AND CORRELATIONS}

The experimental results discussed above can be correlated by the following empirical set of differential equations:

$\dot{m}_{\mathrm{b}}=\rho_{\mathrm{u}} A_{\mathrm{f}} s_{\mathrm{l}}+\mu / \tau_{\mathrm{b}}$

$$
\dot{\mu}=\rho_{\mathrm{u}} A_{\mathrm{f}} u_{\mathrm{T}}-\mu / \tau_{\mathrm{b}},
$$

where $\mu$ is a dummy variable with the dimensions of a mass, $\tau_{\mathrm{b}}$ a characteristic time, and $u_{\mathbf{T}}$ a characteristic speed.

To complete this set of equations, a relationship between $r_{\mathrm{f}}$ and $r_{\mathrm{b}}$ is needed. The data in Fig. 13 suggest that as $r_{\mathrm{b}} \rightarrow 0$ the ratio $r_{\mathrm{f}} / r_{\mathrm{b}} \rightarrow 1$, while for $r_{\mathrm{b}} \rightarrow \infty$ the difference $r_{\mathrm{f}}-r_{\mathrm{b}} \rightarrow u_{\mathrm{T}} \tau_{\mathrm{b}}$. An em. pirical equation satisfying these requirements and fitting the data is

$r_{\mathrm{f}}=r_{\mathrm{b}}+L_{\mathrm{T}}\left(1-\exp \left(-\left(r_{\mathrm{b}} / L_{\mathrm{T}}\right)^{2}\right)\right)$,

where

$L_{\mathbf{T}}=u_{\mathrm{T}} \tau_{\mathrm{b}}$ 
TABLE 4

Summary of Burning and Propagation Angles

\begin{tabular}{|c|c|c|c|c|c|c|c|c|}
\hline Run no. & 1 & 2 & 3 & 4 & 5 & 6 & 7 & \\
\hline$N$ (rpm) & 872 & 1044 & 1099 & 1108 & 1123 & 1220 & 1233 & \\
\hline$\phi$ & 1.09 & 0.98 & 1.14 & 1.02 & 1.08 & 1.13 & 1.07 & Run ave \\
\hline \multirow[t]{3}{*}{$\theta^{*}(\mathrm{deg})$} & $23^{a}$ & 30 & 31 & 28 & 30 & 31 & 30 & $29(3)$ \\
\hline & $31^{b}$ & 39 & 30 & 35 & 34 & 35 & 35 & $34(3)$ \\
\hline & $29(4)^{c}$ & $41(5)$ & $34(5)$ & $33(3)$ & $33(3)$ & $36(4)$ & $36(4)$ & $35(4)$ \\
\hline \multirow[t]{3}{*}{${ }^{\theta} \mathbf{D}$} & 15 & 19 & 21 & 20 & 21 & 21 & 22 & $20(2)$ \\
\hline & 21 & 26 & 20 & 25 & 23 & 25 & 25 & $24(2)$ \\
\hline & $21(1)$ & $28(3)$ & $22(3)$ & $24(3)$ & $23(2)$ & $25(2)$ & $26(2)$ & $24(2)$ \\
\hline \multirow[t]{3}{*}{${ }^{\theta} \mathbf{D}^{\prime}$} & 5 & 6 & 7 & 4 & 6 & 6 & 7 & $6(1)$ \\
\hline & 9 & 14 & 7 & 10 & 7 & 9 & 9 & $9(2)$ \\
\hline & $8(1)$ & $\cdot 12(2)$ & $9(3)$ & $9(2)$ & $8(2)$ & $8(1)$ & $11(2)$ & $9(2)$ \\
\hline \multirow[t]{3}{*}{$\theta_{\mathbf{B}}$} & 20 & 23 & 23 & 14 & 22 & 20 & 19 & $20(3)$ \\
\hline & 25 & 34 & 18 & 19 & 18 & 23 & 20 & $22(6)$ \\
\hline & $21(3)$ & $29(5)$ & $24(4)$ & $24(4)$ & $24(4)$ & $26(7)$ & $25(5)$ & $25(2)$ \\
\hline \multirow[t]{3}{*}{$\theta_{\mathrm{B}^{\prime}}$} & 33 & 34 & 38 & 32 & 34 & 37 & 38 & $35(2)$ \\
\hline & 38 & 41 & 31 & 35 & 34 & 35 & 37 & $36(3)$ \\
\hline & $36(4)$ & $43(4)$ & $35(4)$ & $37(3)$ & $39(4)$ & $39(5)$ & $39(4)$ & $38(3)$ \\
\hline \multirow[t]{3}{*}{$\theta_{\mathbf{T}}$} & 35 & 42 & 44 & 34 & 43 & 41 & 41 & $40(4)$ \\
\hline & 47 & 60 & 38 & 43 & 41 & 47 & 45 & $46(7)$ \\
\hline & $43(3)$ & $56(5)$ & $46(6)$ & $48(4)$ & $47(5)$ & $41(8)$ & $51(7)$ & $49(4)$ \\
\hline \multirow[t]{3}{*}{$\theta_{\mathbf{T}}^{\prime}$} & 38 & 40 & 45 & 36 & 40 & 43 & 45 & $41(3)$ \\
\hline & 47 & 55 & 38 & 45 & 41 & 44 & 46 & $45(5)$ \\
\hline & $44(3)$ & $55(5)$ & $44(4)$ & $46(3)$ & $47(5)$ & $49(6)$ & $50(5)$ & $48(4)$ \\
\hline \multirow{3}{*}{$x_{\mathrm{b}}{ }^{*}(\%)$} & 41 & 49 & 44 & 54 & 51 & 48 & 44 & $47(5)$ \\
\hline & 39 & 42 & 55 & 55 & 60 & 41 & 49 & $49(8)$ \\
\hline & $45(7)$ & $50(6)$ & $49(7)$ & $45(8)$ & $50(7)$ & $46(7)$ & $44(7)$ & $47(3)$ \\
\hline
\end{tabular}

a Numbers in first row following a parameter are for first cycle.

$b$ Numbers in second row following a parameter are for second cycles.

$c$ Numbers in third row following a parameter are averages excluding first cycle; numbers in parentheses are standard deviations of point from averages.

is a characteristic turbulent flame thickness. It is noteworthy that this thickness is of the same magnitude as the characteristic flame radius $l_{c}$ [defined by Eq. (7)] at which the position of the flame center stabilizes.

Alternatively, Eqs. (34) and (35) may be written in terms of the useful characteristic length

$l_{\mathrm{T}}=s_{\mathrm{I}} \tau_{\mathrm{b}}$

instead of the characteristic time $\tau_{\mathbf{b}}$.

Equations (34) are mathematically equivalent to those previously proposed by Blizard and Keck [23] except for the important additional term $\rho_{\mathrm{u}} A_{\mathrm{f}} s_{\mathrm{l}}$ in Eq. (34a). This term is necessary to de- scribe correctly the observed dependence of the initial burning rate on the laminar flame speed $s_{1}$.

The asymptotic behavior of the burning equations in four important limits is as follows:

(i) quiescent charge, $u_{\mathrm{T}} \rightarrow 0$ or $l_{\mathrm{T}} \rightarrow \infty$,

$s_{\mathrm{b}} \cong s_{1}$;

(ii) quasi-steady state, $\dot{\mu} \cong 0$,

$s_{\mathrm{b}} \cong u_{\mathrm{T}}+s_{\mathrm{l}}$

(iii) initial burning, $t \underset{<}{\sim} \tau_{\mathbf{T}}=l_{\mathbf{T}} / u_{\mathbf{T}}$,

$\frac{s_{\mathrm{b}}}{s_{\mathrm{l}}} \cong 1+\frac{t}{3 \tau_{\mathrm{Ts}}}=1+\frac{1}{3}\left(\frac{u_{\mathrm{T}}}{u_{\mathrm{f}}}\right)_{\mathrm{s}} \frac{r_{\mathrm{f}}}{l_{\mathrm{Ts}}} ;$ 


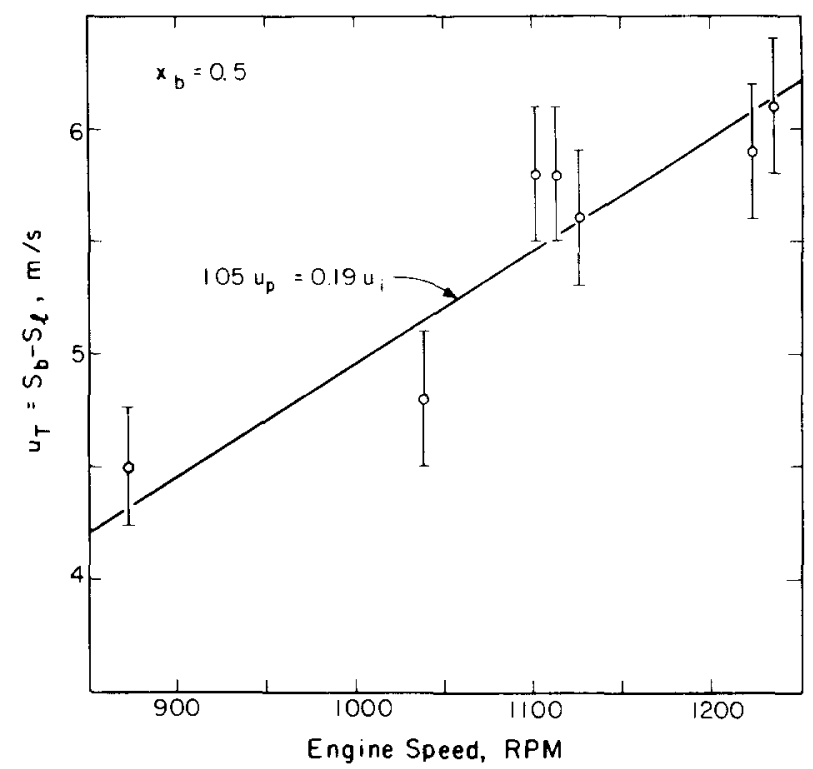

Fig. 19. Characteristic speed $u_{\mathrm{T}} \cong u_{\mathrm{T}} *$ as a function of engine speed.

(iv) final burning, $t \geqslant t_{\mathbf{F}}\left(A_{\mathbf{f}}=0\right)$,

$$
\frac{\dot{m}_{\mathrm{b}}}{m_{\mathrm{b} \mathrm{F}}} \cong e^{-\left(t-t_{\mathrm{F}}\right) / \tau_{\mathrm{b}}}
$$

These limiting expressions were suggested by the experimental data and were used in determining the form of the empirical burning equations (34). For the purpose of interpreting the physical meaning of the proposed burning equations, it is noteworthy that the dummy variable $\mu$ defined by Eqs. (34) is related to previously defined quantities by the relations

$$
\begin{aligned}
\mu & =\tau_{\mathrm{b}}\left(\dot{m}_{\mathrm{b}}-\rho_{\mathrm{u}} s_{\mathrm{l}} A_{\mathrm{f}}\right)=\rho_{\mathrm{u}} l_{\mathrm{T}}\left(A_{1}-A_{\mathrm{f}}\right), \\
\dot{\mu} & =\rho_{\mathrm{u}} A_{\mathrm{f}}\left(u_{\mathrm{T}}+s_{\mathrm{l}}\right)-\dot{m}_{\mathrm{b}} \\
& =\rho_{\mathrm{u}} A_{\mathrm{f}} u_{\mathrm{T}}-\rho_{\mathrm{u}}\left(A_{1}-A_{\mathrm{f}}\right) s_{1} .
\end{aligned}
$$

However, in accordance with the aim of this work, the development of physical models to explain the present experimental observations will be left for future work.

\subsection{Parameters of the Burning Equations}

The burning equations (34) and (35) contain three parameters, $s_{1}, u_{\mathrm{T}}$, and $l_{\mathrm{T}}$, which in principle could be obtained from fundamental chemical kinetic and turbulence models but which in the present analysis were obtained from experimental measurements.

The laminar flame speed $s_{1}$ can be measured using laboratory burners and constant volume bombs, and values are already available in the literature for a variety of practical fuels burning under enginelike conditions. Values for $u_{T}$ can be obtained from engine data of the type shown in Fig. 15 and Table 3 . Assuming quasi-steady state at $\theta^{*}$, Eq. (38) yields $u_{\mathrm{T}} \cong u_{\mathrm{T}} *$. A plot of $u_{\mathrm{T}}{ }^{*}$ as a function of engine speed is shown in Fig. 19. The error bars show the standard deviations of the mean values for all cycles of a given run. The data are well correlated by the relations

$u_{\mathrm{T}}^{*}=1.05 \bar{u}_{\mathrm{p}}=0.19 \bar{u}_{i}$,

where $\bar{u}_{\mathrm{p}}=2 N S$ is the mean piston speed, $\bar{u}_{\mathrm{i}}=$ $\epsilon_{\mathrm{v}}\left(A_{\mathfrak{p}} / A_{\mathrm{IV}}\right) \bar{u}_{\mathfrak{p}}$ the mean inlet gas speed, $N$ the engine speed, $S$ the stroke, $\epsilon_{\mathrm{v}} \cong 0.95$ the volumetric efficiency, $A_{\mathfrak{v}}$ the piston area, and $A_{\text {IV }}$ the maximum open area of the inlet value. Equation (42) is in good agreement with the correlation $s_{\mathrm{b}}=$ $0.22 \bar{u}_{\mathrm{i}}$ found by Blizard and Keck [23] for the quasi-steady flame propagation phase. Measurements of $u_{\mathrm{f}}$ and $s_{\mathrm{b}}$ have also been made by Mattavi et al. [24] and Groff and Matekunas [25] in a 


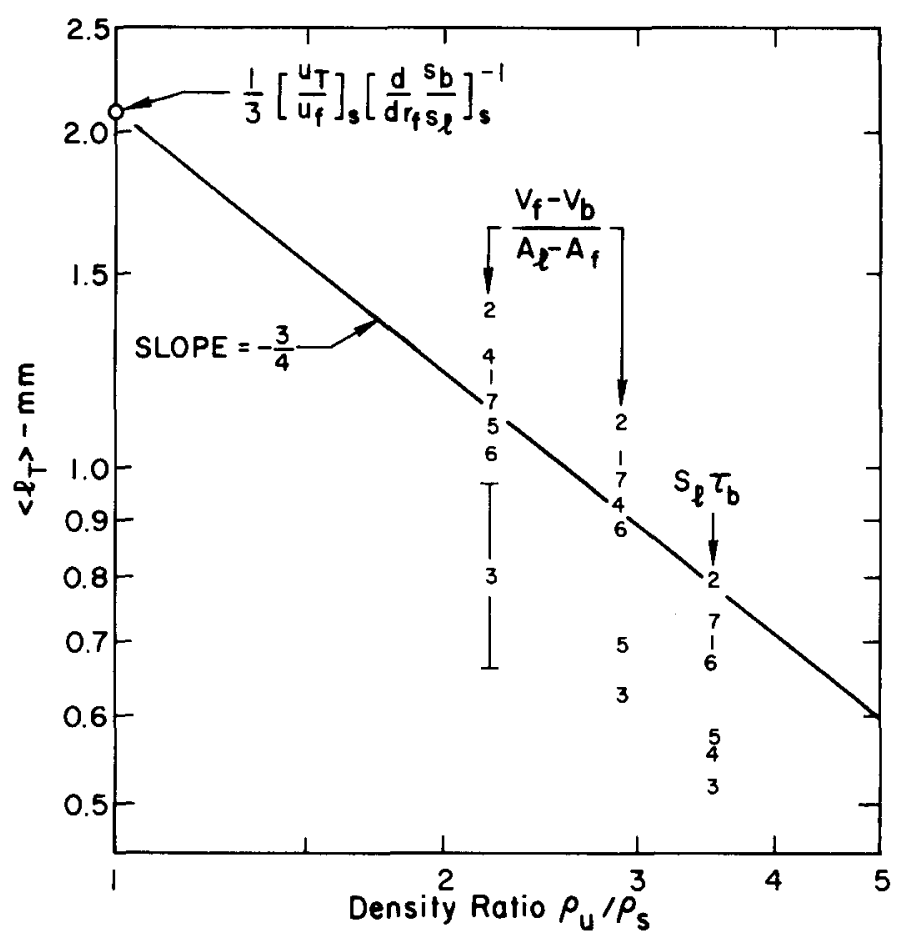

Fig. 20. Characteristic length $l_{\text {T }}$ calculated from various expressions as a function of the density ratio $\rho_{\mathbf{u}} / \rho_{\mathbf{s}}$. Numbers refer to runs.

transparent piston engine similar to that used in the present work, and estimates of $s_{b}$ have been made by Lancaster et al. [26] in a CFR engine from pressure measurements only. Their results are in general agreement with those presented here. In addition, they found a strong correlation between $s_{\mathbf{b}}$ and the turbulence intensity $u^{\prime}$ measured in motored engines [27-32], but did not correlate their data with inlet gas speed.

Values for $l_{T}$ are shown as a function of the density ratio $\rho_{\mathfrak{u}} / \rho_{\mathbf{s}}$ in Fig. 20. Three different methods were used to determine this parameter at different times during combustion. For values of $x_{\mathrm{b}} \approx 0.2$, the definition

$$
l_{\mathrm{T}}=\left(V_{\mathrm{f}}-V_{\mathrm{b}}\right) /\left(A_{\mathrm{l}}-A_{\mathrm{f}}\right)
$$

was used in conjunction with data of the type shown in Fig. 14a. This expression cannot be used for smaller values of $x_{\mathrm{b}}$, since it becomes indeterminate; i.e., it approaches $0 / 0$ as $x_{b}$ approaches 0 . For $x_{\mathbf{b}}=0$, the expression

$$
l_{\mathrm{Ts}}=\frac{1}{3}\left(\frac{u_{\mathrm{T}}}{u_{\mathrm{f}}}\right)_{\mathrm{s}}\left(\frac{d}{d r_{\mathrm{f}}}\left(\frac{s_{\mathrm{b}}}{s_{\mathrm{l}}}\right)\right)_{\mathrm{s}}^{-1}
$$

obtained from Eq. (39) was used in conjunction with data of the type shown in Fig. 15b and Table 3 . Finally, for $x_{\mathrm{b}} \rightarrow 1$ the expression

$l_{\mathrm{T}}=s_{\mathrm{l}} \tau_{\mathrm{b}}$

was used in conjunction with data of the type shown in Fig. 14b.

The values of $l_{\mathrm{T}}$ at $\rho_{\mathrm{u}} / \rho_{\mathrm{S}}=1\left(x_{\mathrm{b}}=0\right)$ obtained using Eq. (44) showed surprisingly little run-torun scatter, and only the average for all runs is shown. The points at $\rho_{\mathrm{u}} / \rho_{\mathrm{s}}=2.2$ and $2.9\left(x_{\mathrm{b}}=\right.$ 0.2 and 0.5 ) are average values for individual runs and were obtained using $\mathrm{Eq}$. (43). The points at $\rho_{\mathrm{u}} / \rho_{\mathrm{s}}=3.5\left(x_{\mathrm{b}}=1\right)$ are also average values for individual runs and were obtained using Eq. (45). The standard deviation of the cycle-to-cycle fluctuations was approximately $\pm 20 \%$ and is shown by the representative error bar. Although the run-torun scatter is quite large, the points at various densities for a given run are fairly strongly correlated, suggesting that the scatter is not entirely due to data errors. To a first approximation

$l_{\mathrm{T}} \cong 2\left(\rho_{\mathrm{s}} / \rho_{\mathrm{u}}\right)^{3 / 4} \quad \mathrm{~mm}$. 
The value of $l_{T}$ at spark and the trend with density given by Eq. (46) are in reasonable agreement with measurements reported by Namazian et al. [33]. These authors quote a value of $l_{\mathrm{T}} \sim$ $1.8 \mathrm{~mm}$ for small $x_{\mathbf{b}}$, and a value of $l_{\mathbf{T}} \sim 0.5 \mathrm{~mm}$ for $x_{\mathrm{b}} \sim 0.4$ may be deducted from the curves in their Fig. 17. Measurements of $l_{\mathrm{T}}$ at spark have also been made by Blizard and Keck [23], who obtained a correlation of the form

$l_{\mathrm{Ts}}=0.17 L_{\mathrm{IV}}\left(\rho_{\mathrm{i}} / \rho_{\mathrm{u}}\right)$

where $L_{\mathrm{IV}}$. is the maximum inlet valve lift and $\rho_{\mathrm{i}}$ is the inlet gas density. Although the density dependence of Eq. (47) is in reasonable agreement with that of Eq. (46), the magnitude of $l_{\mathrm{T}}$ at spark predicted by Eq. (47) for the present experimental conditions is only about one-fifth the value measured. This is due to the omission of the term $\rho_{\mathrm{u}} A_{\mathrm{f}} s_{1}$ in the Blizard-Keck equation corresponding to Eq. (34). If this term is included, Blizard and Keck's data give values for $l_{\text {Ts }}$ in agreement with those given by Eq. (46). A general correlation which fits all the data cited above is

$l_{\mathrm{T}}=0.8 L_{\mathrm{IV}}\left(\rho_{\mathrm{J}} / \rho_{\mathrm{u}}\right)^{3 / 4}$

\section{SUMMARY AND CONCLUSIONS}

Simultaneous pressure measurements and highspeed motion pictures of the visible flame in a spark ignition engine show that the initial flame front propagation speed is very close to that of a laminar flame for the same charge. As the flame grows, its speed increases rapidly to a quasi-steady value of order 10 times the laminar value. During the rapid quasi-steady propagation phase, a significant fraction of the gas entrained behind the visible flame front is unburned. The measurements also suggest that the final combustion phase can be approximated by an exponentially decreasing burning rate with a time constant of order $1 \mathrm{~ms}$.

Detailed analysis of the data has led to the development of a set of empirical differential equations that correlate well the experimental observations. The burning equations contain three parameters: the laminar burning speed of the charge $s_{1}$, a characteristic speed $u_{\mathrm{T}}$, and a characteristic length $l_{T}$. Measurements of $s_{\mathbf{l}}$ under enginelike conditions can be made in constant volume combustion bombs, and values for a number of common fuels are available. Values for $u_{\mathbf{T}}$ and $l_{\mathbf{T}}$ can be obtained from engine experiments, and preliminary correlations for relating these parameters to engine geometry and operating variables have been given. The data suggest that $u_{\mathrm{T}}$ increases and $l_{\mathrm{T}}$ decreases during compression of the unburned gas. For a given engine cycle, the parameters in the burning equations can be adjusted to fit the observed pressure curve. Cycle-to-cycle fluctuations in pressure can be caused by variations in any of the parameters $s_{1}, u_{\mathbf{T}}$, and $l_{\mathbf{T}}$. Variations in $s_{1}$ can be caused by incomplete mixing of the fresh charge with burned residual gas in the cylinder and by variations in the stoichiometry of the fresh charge. Variations in $u_{\mathbf{T}}$ and $l_{\mathbf{T}}$ are presumably associated with the statistical character of turbulence.

An additional parameter required to close the burning equations with a geometrical description of the enflamed region is the vector $\underline{r}_{\mathrm{c}}$ giving the position of the apparent flame center. The nominal value of $\underline{r}_{c}$ is determined by spark plug position, but convection of the flame kernel at early times during propagation can produce significant displacement. It is observed that substantial cycle-tocycle fluctuations can be caused by variations in the parameter $\underline{r}_{\mathrm{c}}$. Variations in $\underline{r}_{\mathrm{c}}$ are presumably caused by convection of the initial flame kernel in the flow field near the spark plug. In this connection, it may be noted that a correlation between the pressure and the flow velocity $\dot{r}_{\mathrm{c}}$ near the spark has been observed in laser doppler measurements made by Cole and Swords [34].

Although the proposed empirical burning equations provide a relatively simple and accurate method of predicting the observed burning rates in spark ignition engines, the range of engine geometries and operating variables investigated in this experiment is relatively small and needs to be considerably extended. In particular, systematic investigations over a wide range of engine speeds, spark angles, valve lifts, and compression ratios are needed to establish the proper correlations for $u_{\mathrm{T}}$ and $l_{\mathrm{T}}$. The origin of the cyclic variations in the values of $s_{1}, u_{\mathrm{T}}, l_{\mathrm{T}}$, and $r_{\mathrm{c}}$ needs to be more 
closely examined, and correlations for relating their magnitudes to engine geometry and operating conditions need to be developed. The range of validity of the burning equations and their applicability, for example, to engines with significant swirl and squish also needs to be established. Finally, the experimental evidence presented and the proposed empirical equations need to be better understood in terms of the underlying physical mechanisms.

\section{NOMENCLATURE 1}

$a_{\mathrm{f}}$ dimensionless flame front area

$a_{1}$ dimensionless equivalent laminar burning area

$A \quad$ area

$A_{\mathrm{b}} \quad$ equivalent spherical burning rate

$A_{\mathrm{c}} \quad$ area of "best fit" circle

$A_{\mathrm{f}} \quad$ flame front area

$A_{1} \quad$ equivalent laminar burning area

$A_{\mathrm{p}} \quad$ piston surface area

$c_{\mathfrak{v}} \quad$ specific heat at constant pressure

$c_{\mathbf{v}} \quad$ specific heat at constant volume

$h$ mean clearance height $\left(=V / A_{\mathrm{p}}\right)$

$l_{c} \quad$ characteristic radius for stabilization of flame center

$l_{\mathrm{T}} \quad$ characteristic length

$L_{\text {c }} \quad$ arc length of "best fit" circle

$L_{\mathbf{T}} \quad$ characteristic turbulent flame thickness $\left(=u_{\mathrm{T}} \tau_{\mathrm{b}}\right)$

$m$ mass of gas in combustion chamber (excluding crevices)

$N \quad$ engine speed (revolutions/minute)

$p \quad$ pressure

$r$ radius

$r_{\mathrm{b}} \quad$ equivalent burned gas radius

$\underline{r}_{\mathbf{c}}$, location of center of "best fit" circle $\left(r_{\mathrm{c}}=\left|\underline{r}_{\mathrm{c}}\right|\right)$

$r_{\mathrm{cs}}$ displacement of flame center from spark plug

$r_{t} \quad$ "best fit" flame radius

$R \quad$ radius of combustion chamber $(=b / 2)$

$S \quad$ speed

$s_{\mathrm{b}} \quad$ burning speed

$s_{1} \quad$ laminar burning speed

$t$ time

$T$ temperature

1 See also Tables 1 and 2.

\begin{tabular}{|c|c|}
\hline$u$ & expansion speed \\
\hline$b_{\mathrm{b}}$ & mean burned gas expansion speed \\
\hline$t_{\mathrm{c}}$ & speed of flame center \\
\hline & mean flame front expansion speed \\
\hline & $\begin{array}{l}\text { unburned gas speed just ahead of flame } \\
\text { front }\end{array}$ \\
\hline & mean inlet gas speed \\
\hline lo & mean piston speed \\
\hline & characteristic speed \\
\hline & $\begin{array}{l}\text { volume of combustion chamber (excluding } \\
\text { crevices) }\end{array}$ \\
\hline & mass fraction \\
\hline & volume \\
\hline & ratio of specific heats $\left(=c_{p} / c_{v}\right)$ \\
\hline$\delta_{c}$ & $\begin{array}{l}\text { displacement of stable flame center from } \\
\text { spark plug }\end{array}$ \\
\hline$\varepsilon_{\mathrm{v}}$ & volumetric efficiency \\
\hline & crank \\
\hline$\theta_{\mathrm{B}}$ & fast burning angle \\
\hline$\theta_{\mathbf{B}}^{\prime}$ & fast propagation angle \\
\hline$\theta_{D}$ & burning delay angle \\
\hline$\theta_{\mathbf{D}}^{\prime}$ & propagation delay angle \\
\hline$\theta_{\mathbf{T}}$ & total burning angle \\
\hline$\theta_{\mathbf{T}}^{\prime}$ & total propagation angle \\
\hline$\theta_{\mathbf{F}}$ & crank angle when flame hits far wall \\
\hline$\theta_{\mathrm{N}}$ & crank angle when flame hits near wall \\
\hline & dummy variable with dimensions of mass \\
\hline & density \\
\hline 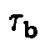 & characteristic time \\
\hline 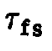 & characteristic initial flame acceleration time \\
\hline & initial burning characteristic time $\left(=l_{\mathrm{T}} / u_{\mathrm{T}}\right)$ \\
\hline & uivalence ratio \\
\hline$\chi_{\mathbf{c}}$ & angular displacement of center of "best fit" \\
\hline
\end{tabular}

\section{Subscripts and Superscripts}

b burned gas

c "best fit" circle

f enflamed volume

$\mathrm{m}$ motoring conditions

o conditions outside thermal boundary layer

s conditions at spark time

u unburned gas

* conditions at maximum mass burning rate

The authors would like to thank Professor John B. Heywood for his valuable critical help during 
the course of this work. The work was supported in part by NASA under Grant Number NSG-3245 and in part by the M.I.T. Energy Laboratory.

\section{REFERENCES}

1. Mattavi, J. N., and Amman, C. A., Eds., Combustion Modeling in Reciprocating Engines, Plenum Press, New York, 1980.

2. Batchelor, G. D., The Theory of Homogenous Turbulence, Cambridge University Press, Great Britain, 1954.

3. Orszag, S. A., J. Fluid Mechanics 41:363 (1970).

4. Townsend, A. A., J. Fluid Mechanics 41:13 (1970).

5. Launder, B. E., and Spalding, D. B., Mathematical Models of Turbulence, Academic Press, New York, 1972.

6. Tennekes, H., and Lumley, J. L., A First Course in Turbulence, M.I.T. Press, Cambridge, MA, 1972.

7. Pope, S. B., Phil. Trans. R. Soc. Lond. 291:529 (1979).

8. Morel, T., and Mansour, N. N., SAE Paper 820040 presented at the International Congress and Exposition, February 1982.

9. Andrews, G. E., Bradley, D., and Lwakabamba, S. B., Combust. Flame 24:285 (1975).

10. Chomiak, J., Sixteenth Symposium (International) on Combustion, The Combustion Institute, 1976, p. 1665 .

11. Spalding, D. B., Combust. Sci. and Technology 13:3 (1976).

12. Tabaczynski, R. J., Prog. Energy Combust. Sci. 2:143 (1976).

13. Bray, K. N. C., Turbulent Reacting Flows (Libby, P. A., and Williams, F. A., Eds.), Springer-Verlag, Heidelberg and New York, 1980.

14. Oran, E. S., and Boris, J. P., Prog. in Energy and Comb. Sci. 7:1 (1981).

15. Libby, P. A., and Bray, K. N. C., AIAA J. 19:205 (1981).

16. Libby, P. A., and Williams, F. A., Combust. Flame 44:287 (1982).

17. Beretta, G. P., Rashidi, M., and Keck, J. C., Paper WSS/CI 80/20 presented at the Spring Meeting of the Western States Section of the Combustion Institute, April 1980.
18. Keck, J. C., Nineteenth Symposium (International) on Combustion, The Combustion Institute, to be published.

19. Rashidi, M., The Institution of Mechanical Engineers, Proceedings 194:231 (1980). See also Combust. Flame 42:111 (1981).

20. Lavoie, G. A., Heywood, J. B., and Keck, J. C., Combust. Sci. and Technology 1:313 (1970). See also Beretta, G. P., and Keck, J. C., Combust. Sci. and Technology 30:19 (1983).

21. Woschni, G., SAE Paper 670931 (1967).

22. Metghalchi, M., and Keck, J. C., Combust. Flame 48:191 (1982).

23. Blizard, N. C., and Keck, J. C., SAE Paper 740191 presented at the Automotive Engineering Congress, February 1974.

24. Mattavi, J. N., Groff, E. G., Lienisch, J. N., Matekunas, F. A., and Noyes, R. N., in Combustion Modeling in Reciprocating Engines (Mattavi, J. N., and Amman, C. A., Eds.), Plenum Press, New York, 1980 , p. 537.

25. Groff, E. G., and Matekunas, F. A., Paper No. 800133, SAE Trans. 89:740 (1980).

26. Lancaster, D. R., Krieger, R. B., Sorenson, S. C., and Hull, W. L., Paper No. 760160, SAE Trans. 85:689 (1976).

27. Lancaster, D. R., SAE Paper 760159, 1976.

28. Tsuge, B. M., Kido, H., and Yanagihara, H., Bull. of the JSME 16:244 (1973).

29. Tsuge, B. M., Kido, H., Kato, K., and Nomiyama, Y., Bull. of the JSME 17:587 (1974).

30. James, E. H., and Lucas, G. G., SAE Paper 750885, 1975 .

31. Dent, J. C., and Salama, N. S., SAE Paper 750886, 1975.

32. Witze, P. O., SAE Paper 770220, 1977.

33. Namazian, M., Hansen, S., Lyford-Pike, E., SanchezBarsse, J., Heywood, J., and Rife, J., SAE Paper 800044 presented at the International Congress and Exposition, February 1980.

34. Cole, J. B., and Swords, M. D., SAE Paper 800043 presented at the International Congress and Exposition, February 1980.

Received 27 October 1982; revised 7 March 1983 